IIIIIIIIIIIIIIIIIIIIIIIIIIIIIIIII

Review Article

IIIIIIIIIIIIIIIIIIIIIIIIIIIIIIII

\title{
In vitro metabolism of pesticides and industrial chemicals in fish
}

\author{
Toshiyuki Katagi \\ Bioscience Research Laboratory, Sumitomo Chemical Co., Ltd., 3-1-98 Kasugadenaka, Konohana-ku, Osaka 554-8558, Japan
}

(Received November 19, 2019; Accepted December 19, 2019)

\begin{abstract}
Metabolism is one of the most important factors in controlling the toxicity and bioaccumulation of pesticides in fish. In vitro systems using subcellular fractions, cell lines, hepatocytes and tissues of a specific organ, each of which is characterized by usability, enzyme activity and chemical transport via membrane, have been applied to investigate the metabolic profiles of pesticides. Not only species and organs but also the fishkeeping conditions are known to greatly affect the in vitro metabolism of pesticides. A comparison of the metabolic profiles of pesticides and industrial chemicals taken under similar conditions has shown that in vitro systems using a subcellular S9 fraction and hepatocytes qualitatively reproduce many in vivo metabolic reactions. More investigation of these in vitro systems for pesticides is necessary to verify their applicability to the estimation of pesticide metabolism in fish.
\end{abstract}

Keywords: in vitro metabolism, S9, microsome, cytosol, hepatocyte, pesticide.

\section{Introduction}

Fish are standard aquatic species, along with daphnia and algae, generally utilized to assess the ecotoxicological impacts of pesticides and industrial chemicals in an aquatic environment. The various acute and chronic studies of these chemicals are generally conducted via water or dietary exposure to examine their toxicity and potential of bioaccumulation, and many researchers have also been investigating endocrine disruption and synergistic combined toxicity as recent concerns. ${ }^{1)}$ Although the primary exposed organ of fish depends on the route of exposure, e.g., gills via water and the gastrointestinal tract via food, the chemical taken up is finally distributed to each organ by the circulation of blood. ${ }^{2-4)}$ Chemicals, including pesticides, are partitioned to fat depending on their hydrophobicity, and the remaining part is subjected to metabolic transformation in many organs, such as the liver, kidney, and gills, for more efficient elimination via urine, feces, and ventilation. In the case of dietary exposure, microorganisms in the gastrointestinal tract may play an additional metabolic role. ${ }^{5)}$ Metabolism generally results in the detoxification of a chemical but sometimes increases its toxicity by bioactivation as observed with phosphorothioate pesticides, and it reduces the bioaccumulation of a hydropho-

\footnotetext{
To whom correspondence should be addressed.

E-mail: katagi@sc.sumitomo-chem.co.jp

Published online January 24, 2020
}

(c) BY-NC-ND (c) Pesticide Science Society of Japan 2020. This is an open access article distributed under the Creative Commons AttributionNonCommercial-NoDerivatives 4.0 International (CC BY-NC-ND 4.0) License (https://creativecommons.org/licenses/by-nc-nd/4.0/) bic chemical by its transformation to more polar metabolites. ${ }^{3,4)}$ Therefore, metabolism becomes a key factor in evaluating the PBT (persistent, bioaccumulative and toxic) ${ }^{6)}$ character of pesticides and industrial chemicals and estimating the nature of pesticide residues in fish fed with plant commodities. ${ }^{7)}$

In order to clarify the risk of a chemical before commercialization, the relevant regulation should require hazard information, which derives from in vivo toxicity studies using a large number of fish. ${ }^{1,8)}$ However, there are so many chemicals, including pesticides, to be assessed that, from the economic and ethical viewpoints, it is not practical to conduct in vivo studies for all of them. Under these circumstances, many regulations encourage the development and use of alternative methods based on the $3 \mathrm{R}$ (replace, reduce and refine) principle. ${ }^{8,9)}$ One approach in fish metabolism is to reduce the number of fish and the testing concentration in the existing test methods, ${ }^{10)}$ but it is still cumbersome to estimate the metabolic rate constant $\left(k_{\mathrm{M}}\right)^{11)}$ and identify relevant metabolites to be further assessed. Another is an in silico approach, such as QSAR and toxicokinetics based on the mode of action, which successfully estimated the uptake and elimination rates of a chemical at a satisfactory level by using its $\log K_{\mathrm{ow}}$ and molecular descriptors. ${ }^{8,9)}$ However, the application of this method to the estimation of $k_{\mathrm{M}}$, which is the single most influential factor in toxicokinetics, ${ }^{12,13)}$ is insufficient, ${ }^{14)}$ and no concrete information on metabolites is available. As an alternative experimental approach, in vitro methods using subcellular fractions or hepatocytes have been conveniently utilized to obtain the depletion rate constant of a chemical in fish. ${ }^{15)}$ This value can be extrapolated to an in vivo hepatic clearance using the IVIVE (in vitro-in vivo extrapolation) method, where a hepatic blood flow and a free fraction of a chemical therein are used on the basis of the well-stirred liver 
model. ${ }^{15-17)}$ This method has been successfully applied to pesticides, pharmaceuticals, polyaromatic hydrocarbons (PAHs), and ionizable chemicals, as described in OECD guidance document No. 280, ${ }^{15)}$ the international ring trial ${ }^{18)}$ and other references, ${ }^{19,20)}$ and it plays a great role in estimating their bioconcentration factor in fish at a satisfactory level. Furthermore, the risk assessment of relevant metabolites in fish has been recently required especially in the EU regulation of pesticides. ${ }^{1)}$ Since in vitro systems utilized to estimate the depletion rate constant of a chemical basically contain metabolic enzymes in original organs, they are expected to exhibit metabolic profiles similar to those in in vivo fish studies. ${ }^{15,16)}$

In this review, we first introduce several in vitro approaches investigating metabolism in fish. After discussing the relevant metabolic enzymes and metabolism-controlling factors, the in vitro metabolism of pesticides and industrial chemicals using subcellular fractions and hepatocytes is summarized. Although the available information is limited, we discuss the applicability of in vitro methods by referring to the corresponding in vivo studies. Finally, an overview summary is provided, including issues that should be kept in mind when conducting in vitro metabolism studies of pesticide in fish, and the unclear issues to be further investigated.

\section{In Vitro Methods of Fish Metabolism}

Metabolism generally proceeds in two steps: a chemical is first transformed to more polar metabolites by oxidation and/or hydrolysis (phase I), followed by conjugation with endogenous molecules (phase II) such as glucuronic acid (GA) and glutathione (GSH). ${ }^{2-4,12)}$ The primary organ of metabolism is the liver, and others, such as the kidney, intestine, and gills, are known to have a comparative extrahepatic activity. ${ }^{3)}$ Therefore, in vitro methods being developed should represent the enzyme activity in an original organ at a satisfactory level.

\subsection{Subcellular fractions}

Metabolic enzymes catalyzing phase I and II reactions are distributed throughout a cell, and most of them are localized in the smooth endoplasmic reticulum and cytosol. Therefore, the corresponding subcellular fraction is considered to be the primary candidate component for an in vitro system, and the postmitochondrial supernatant (S9) fraction prepared by centrifugation of an organ homogenate, typically of the liver, at $13,000-15,000 \mathrm{~g}$ for $20 \mathrm{~min}$ has been conveniently utilized. ${ }^{21)}$ The $S 9$ fraction can be further fractionated by centrifugation at $105,000 \mathrm{~g}$ for $1 \mathrm{hr}$ into microsomes (pellet) and cytosol (supernatant). In general, the former contains oxidative enzymes such as cytochrome P450 (CYP) and flavin-containing monooxygenases (FMOs) together with esterases and uridine 5' -diphospho-glucuronosyltransferases (UDPGTs), while the latter contains esterases, glutathione-S-transferases (GSTs), and sulfotransferases (SULTs). ${ }^{2-4,12)}$ The typical activity of some enzymes in the hepatic S9 fraction is listed in Table 1. Scarce information on the activity of esterase and SULTs is available for this fraction, but their reported activ- ity in the microsomes and cytosol is highly dependent on both species and substrates. ${ }^{12)}$ For example, the SULT activity ranges from 0.2 to $14 \mathrm{pmol} \mathrm{min}^{-1} \mathrm{mg}^{-1}$ protein in the hepatic cytosol of rainbow trout (Oncorhynchus mykiss). Since acyl transferases are mainly located in the mitochondrial fraction being excluded in the preparation of $S 9,{ }^{22,23)}$ the phase II conjugation with an amino acid should be examined separately.

These subcellular fractions are easy to prepare, and the microsomes and/or cytosol have been utilized to systematically investigate the metabolic reaction catalyzed by each enzyme. Since each enzyme is localized between these fractions, the S9 fraction is considered more suitable to examine the total metabolism of the pesticide. In any case, the active transporters embedded in membranes is absent in the S9 fraction, which is much different from cellular systems. A sufficient amount of the corresponding cofactor should be added to exhibit enzyme activity, and the reaction period of $c a .2 \mathrm{hr}$ is recommended due to the progressive loss of enzyme activity. ${ }^{21)}$ The $S 9$ fractions prepared from several fish should be mixed, because of the variance in enzyme activity. The activity of several CYPs, UDPGTs and GSTs is known to be well preserved for at least 2 years when stored at $-80^{\circ} \mathrm{C}$. $^{24)}$

\subsection{Hepatocytes}

Hepatocytes have been prepared using the two-step perfusion technique with collagenase from the liver of several species, mainly O. mykiss and the common carp (Cyprinus carpio). ${ }^{25)}$ The cell yield in a preparation generally exceeds $90 \%$, with hepatocytes as the main component (ca. 80\%). ${ }^{25,26)}$ Enzyme activity comparable to the hepatic $\$ 9$ fraction has been reported (Table 1), but the preparation is more cumbersome than subcellular fractions. Since the usage of freshly prepared hepatocytes is generally restricted to within $c a$. $4 \mathrm{hr}$ due to cell viability, the cryopreservation method has been developed using liquid $\mathrm{N}_{2}{ }^{25)}$ After thawing the cryopreserved hepatocytes, the activity of ethoxyresorufin-O-deethylase (EROD), GST, and UDPGT was found to be retained well, ${ }^{27)}$ and the depletion study on nine chemicals, including three pesticides showed insignificant effects of cryopreservation on the metabolic activity. ${ }^{18,27,28)}$

Freshly prepared hepatocytes are gradually transformed into monolayers and spheroids ( $c a .500$ cells per spheroid) by aggregation within a week, depending on the incubation method. ${ }^{29}$ ) The presence of fetal bovine serum was indispensable to maintaining a cell viability for a longer period. ${ }^{30}$ The advantage of hepatocytes over subcellular fractions is the retention of all metabolic activities with chemical transporters, but the total CYP content has been reported to gradually decrease after a week with incubation. ${ }^{31,32)}$ The EROD activity showed a convex profile during 30-day incubation, and similar changes in activity were observed for UDPGT depending on the substrates, such as testosterone and 4-nitrophenol, while the GST activity against 1-chloro-2,4-dinitrobenzene (CDNB) increased with incubation. ${ }^{26,32,33)}$ Similarly, the gene expression of these enzymes varied with the aggregation of primary hepatocytes to spheroids, and more genes of ABC (ATP-binding cassette) efflux transport- 
Table 1. Typical activity of metabolic enzymes.

\begin{tabular}{ccllc}
\hline System & Species $^{a)}$ & \multicolumn{1}{c}{ EROD $\left({ }^{\circ} \mathrm{C}\right)^{b)}$} & \multicolumn{1}{c}{ GST $\left({ }^{\circ} \mathrm{C}\right)^{c)}$} & UDPGT $\left({ }^{\circ} \mathrm{C}\right)^{d)}$ \\
\hline Hepatic S9 & RT & $1.1-7.1(10-11)^{18,19,27,28,33,35)}$ & $37-425(10-11)^{18,19,27,28,35)}$ & $0.23-0.31(10-11)^{18,27,35)}$ \\
& & $25-50(20-25)^{36,37)}$ & & \\
Hepatocytes & CT & $1.65(22)^{38)}$ & $83-889(10-11)^{18,39-41)}$ & $0.7-9.2(10-11)^{18,39-41)}$ \\
& RT & $0.65-11.3(10-11)^{18,39-41)}$ & $442(25)^{42)}$ & $177(25)^{42)}$ \\
& FM & $11(25)^{42)}$ & $4.6(25)^{42)}$ & \\
\hline
\end{tabular}

Superscript number means the reference. ${ }^{a)} \mathrm{RT}$, rainbow trout (Oncorhynchus mykiss); CT, catfish (Ictalurus melas); FM, fathead minnow (Pimephales promelas); CC, common carp (Cyprinus carpio). ${ }^{b}$ Ethoxyresorufin-O-deethylase in pmol $\mathrm{min}^{-1} \mathrm{mg}^{-1}$ protein. ${ }^{c}$ Glutathione-S-transferase vs. 1-chloro-2,4dinitrobenzene (CDNB) in nmol min ${ }^{-1} \mathrm{mg}^{-1}$ protein. ${ }^{d}$ Uridine $5^{\prime}$-diphospho-glucuronosyltransferase vs. 4-nitrophenol in $\mathrm{nmol} \mathrm{min}^{-1} \mathrm{mg}^{-1} \mathrm{protein}$

ers were expressed with a spheroid formation. ${ }^{34)}$

\subsection{Cell lines}

The liver is the most important organ in metabolism, and the disadvantage of the method using subcellular fractions can be mostly overcome by using hepatocytes. However, the inconvenience of either preparing fresh hepatocytes or separating viable cells after thawing cryopreserved ones has led to the development of the immortalized cell lines originating from several organs, including the liver, and many of them are commercially available from the American Type Culture Collection. Although these cell lines do not always reflect the original metabolic activity, ${ }^{16)}$ they may be utilized in another in vitro method. For example, cell lines from the embryonic gonad of a rainbow trout (O. mykiss; RTG-2), the cadual trunk of a bluegill fry (Lepomis macrochirus; $\mathrm{BF}-2$ ), and the connective tissue and muscle of a fathead minnow (Pimephales promelas; FHM) or brown bullhead (Ictalurus nebulosus; BB) were used to examine the metabolism of benzo[a]pyrene $(\mathrm{BaP}) .{ }^{43)}$ Both stepwise oxidation of $\mathrm{BaP}$ to carcinogenic (+)-anti-7,8-dihydrodiol-9,10-epoxide and glucuronidation of 7,8-dihydrodiol were highly dependent on the cell line.

Cell lines originating from gills and intestines have also been prepared to examine the extrahepatic metabolism. The $\mathrm{RT}_{\text {gill }}{ }^{-}$ W1 cell line prepared from the respiratory epithelial cells of gill filaments in O. mykiss showed the lower activity of 7-ethoxycoumarin (EC) $O$-deethylase (ECOD) and UDPGT than those in the original organ, but this cell line exhibited no SULT activity. ${ }^{44)}$ This cell line had EROD activity comparable to that of the hepatic S9 fraction, but no formation of $6 \beta-/ 16 \beta-\mathrm{OH}$ testosterone derivatives indicated the lack of CYP3A. The gastrointestinal cell line ( $\mathrm{RT}_{\text {gut }} \mathrm{GC}$ ) expressing CYP3A and GST genes was developed from the gut of $O$. mykiss and found to secrete mucous with the formation of tight junction proteins. ${ }^{45)}$ Recently, the RTL-W1 cell line prepared from the liver of O. mykiss was found to be transformed into spheroids of uniform size and shape by dynamic incubation with an orbital shaker, and transmission electron microscopy revealed the formation of cell-cell junctions. ${ }^{46)}$ The basic EROD activity and its induction by $\mathrm{BaP}$ are highest in RTL-W1, and the metabolic activity in the depletion of $\mathrm{BaP}$ decreases in the order of RTL-W1 $>\mathrm{RT}_{\text {gut }} \mathrm{GC}>\mathrm{RT}_{\text {gill- }}$
W1 ${ }^{47,48)}$ Both the epifluorescence observation of treated cells and the GC-MS analysis of cell extracts clearly indicated the uptake of $\mathrm{BaP}$ by the $\mathrm{RT}_{\text {gut }} \mathrm{GC}$ cells. ${ }^{49)}$

\subsection{Tissue slices}

The tissue architecture with intact cell membranes kept in an ex vivo tissue slice offers a fascinating look at metabolism under a complete cellular environment, but the limited diffusion of a chemical to metabolic enzymes via intact membranes may result in a slower metabolism. ${ }^{16)}$ The ATP and GSH content in O. mykiss liver slices was similar to that in the corresponding hepatocytes, ${ }^{50)}$ while the leakage of lactate dehydrogenase showed that only half of the cells therein were viable after 1-day incubation with the reduced CYP content. ${ }^{51)}$ The liver slices of Atlantic cod (Gadus morhua) showed cell viability up to 3 days, and the expression of the CYP1A gene was induced by $\beta$-naphthoflavone. ${ }^{52)}$ Therefore, their usage for a short period would be appropriate for in vitro metabolism, similarly to the use of hepatocytes.

The comparative metabolism of carbaryl has been examined by using liver slices from several species, and either ring oxidation or hydrolysis followed by conjugation was commonly observed. ${ }^{53)}$ Although the application is still limited, O. mykiss is the main species used in this ex vivo system as described below. Not only the 4-hydroxylation of biphenyl and $O$-deethylation of 7-EC followed by glucuronidation but also the conjugation of 1-naphthol with GA and sulfate proceeded at reaction rates comparable to those of $O$. mykiss hepatocytes. ${ }^{50)}$ Stepwise $O$ demethylation followed by glucuronidation was observed in the metabolism of methoxychlor, but without the formation of a sulfate conjugate. ${ }^{5455)}$ The organophosphorus ester linkage of diazinon was cleaved to form the corresponding pyrimidinol, followed by its glucuronidation. ${ }^{56)}$ Since the addition of 2-hydroxyquinoline, a paraoxonase-I inhibitor, reduced the formation of pyrimidinol, this hydrolysis was likely to proceed via the diazinon oxon.

\section{In Vitro Metabolism}

\subsection{Relevant enzymes}

As briefly described in Section 1.1, two types of transformation, phase I and II, are catalyzed by various enzymes in many aquatic 
species, including fish. ${ }^{2-4,12,57)}$ The typical metabolic reactions are listed in Table 2. Enzymatic hydrolysis of esters and epoxides is one of the most well-known reactions in fish, catalyzed by carboxylesterases, arylesterases, and epoxide hydrolases, as observed in the metabolism of pesticides ${ }^{3)}$ and PAHs. ${ }^{12)}$ Enzymatic oxidation catalyzed by the CYP superfamily in the presence of a cofactor NADPH under $\mathrm{O}_{2}$ is generally the primary phase I reaction, ${ }^{12,57)}$ and the CYP content highly dependent on the fish species is less than that of mammals. ${ }^{58)} \mathrm{CYP} 1-3$ are known to be most active in the fish metabolism of xenobiotics, and EROD is conveniently utilized to measure the CYP1A activity. ${ }^{4,12)}$ FMO is another important oxidase contributing to the oxidation of nucleophilic atoms, such as sulfur, and it catalyzes the oxidation of fenthion and aldicarb to sulfoxides. ${ }^{3,57)}$ Reduction is sometimes observed and can be catalyzed by CYP, but the reactions with endogenous reducing molecules, such as GSH and flavin adenine dinucleotide, should be also taken into account. ${ }^{4)}$

Three types of conjugation proceed mainly as phase II reactions. ${ }^{12,22,57)}$ Glucuronidation at an electron-rich atom, such as oxygen and nitrogen, is catalyzed by many isoforms of UDPGT with UDP glucuronic acid (UDPGA) as a cofactor. ${ }^{12,59)}$ The species-dependent enzyme activity is generally high in the liver, and the corresponding metabolites are frequently detected in bile. ${ }^{60)}$ Sulfate conjugation is another reaction with a high affinity and a low capacity, catalyzed by SULT with phosphoadenosyl phosphosulfate (PAPS) as a cofactor, and several isoforms have also been reported. ${ }^{12)}$ Higher activity is observed in the liver and intestine, and the metabolites, via the reaction of phenolic oxygen and amine nitrogen, are frequently detected in urine. ${ }^{22)}$ The third reaction is the GST-catalyzed conjugation with GSH at the electrophilic site of a substrate, such as CDNB, frequently observed in the liver, intestine, and kidney. ${ }^{12,22)}$ At least nine isoforms are known, and the predominant one depends on the species, for example, the $\pi$-class in cyprinids and salmonids and the $\rho$-class in flatfish and bass. ${ }^{12)}$ The GSH conjugate itself is scarcely detected due to further metabolism through the cysteine conjugate, and a mercapturic acid derivative is frequently detected instead as an end product. ${ }^{3,57)}$ In addition to these main reactions, acetylation and conjugation with an amino acid are sometimes observed in fish metabolism. The $\mathrm{N}$-acetylation of aniline $\mathrm{e}^{44)}$ and conjugation of 2,4-D with taurine ${ }^{3)}$ have been reported, both of which are catalyzed by acyltransferases using an acid-coenzyme A complex as a cofactor. ${ }^{4,12}$

\subsection{Controlling factors}

The contents and activity of metabolic enzymes in fish are highly dependent on species, feeding habits, and habitat, which consequently affect the toxicity and bioaccumulation of a chemical. ${ }^{2,3)}$ Therefore, an in vitro study should be carefully designed and conducted, followed by an adequate interpretation of the results with consideration of the factors below.

\subsubsection{Sex and age}

Since the activity of each metabolic enzyme changes with the development of reproductive organs, the metabolism of pesticides and industrial chemicals may depend on both sex and age. However, the detailed analysis of its age dependence has been scarcely reported. The higher in vivo metabolic activity against benzophenone-2 and bisphenol-S was observed in the adult zebrafish (Danio rerio) with more conjugation with a sulfate than GA, as compared with its embryos. ${ }^{61)}$ The metabolism of pesticides in mammals is generally examined in relation to their gender, while such information is very limited for fish. By the flow-through water exposure of adult cyprinid fish, Scardinius erythrophthalmus, to ${ }^{14} \mathrm{C}$-labeled 4 -tert-octylphenol [4-(1,1,3,3-tetramethylbutyl)phenol], the insignificant differences in ${ }^{14} \mathrm{C}$ distribution between male and female were observed for bile and tissues, except the liver, where more residues were detected in the male. ${ }^{62)}$ There were eight common biliary metabolites in comparable amounts, irrespective of sex. The depletion study of six PAHs using the hepatic S9 fraction of O. mykiss showed no sex dependence with similar activity of EROD, GST, aryl hydrocarbon hydroxylase and UDPGT. ${ }^{41)}$ Insignificant sex differences in the protein and CYP contents were reported for the hepatocytes prepared from immature but sex-determined O. mykiss. ${ }^{27)}$ The clearance of pyrene by these hepatocytes was almost the same between both sexes, together with the activity of EROD, UDPGT and GST. However, it has been reported that the Michaelis-Menten constants of several metabolic enzymes are variably affected by sex. ${ }^{63)}$ Therefore, sexually immature fish should be used to prepare subcellular fractions and hepatocytes

Table 2. Metabolic reactions catalyzed by relevant enzymes.

\begin{tabular}{|c|c|c|}
\hline Metabolism & Code & Reactions \\
\hline \multirow[t]{3}{*}{ Oxidation } & $\mathrm{O} 1$ & $O$ or $N$-dealkyation, $C$-oxidation to form alcohol, phenol, epoxide, and quinone \\
\hline & $\mathrm{O} 2$ & $S$-oxidation to form sulfoxide and sulfone \\
\hline & $\mathrm{O} 3$ & desulfuration, $N$-oxidation, and other oxidation \\
\hline Reduction & $\mathrm{R}$ & dehalogenation, nitro to amino, sulfoxide to sulfide, and ketone to alcohol \\
\hline Hydrolysis & $\mathrm{H}$ & carboxylic or phosphoryl ester, amide, and carbamate \\
\hline \multirow[t]{4}{*}{ Conjugation } & $\mathrm{C} 1$ & glucuronidation \\
\hline & $\mathrm{C} 2$ & sulfonation \\
\hline & $\mathrm{C} 3$ & glutathione conjugation, finally to form mercapturic acid derivative \\
\hline & $\mathrm{C} 4$ & $\mathrm{~N}$-acetylation or amino acid conjugation \\
\hline Miscellaneous & M & ether bond cleavage, rearrangement, and others \\
\hline
\end{tabular}


for in vitro metabolism, in accordance with the OECD guidelines. ${ }^{21,25)}$

\subsubsection{Temperature}

Although the temperature effects on the Michaelis-Menten constants have been reported for several metabolic enzymes, ${ }^{63)}$ such information is very limited for in vitro metabolism. The hydrolysis rate of trans-permethrin was examined using the hepatic S9, microsomal and cytosolic fractions of O. mykiss at 12 and $22^{\circ} \mathrm{C}^{64)} \mathrm{A} 10^{\circ} \mathrm{C}$ increase accelerated the reaction by a factor $\left(\mathrm{Q}_{10}\right)$ of $4.6,4.8$, and 2.8, respectively, showing the major involvement of microsomal enzymes. The enzyme activity of ECOD, UDPGT and BaP hydroxylase in the hepatocytes, prepared from $O$. mykiss acclimated at 4 and $17^{\circ} \mathrm{C}$, was examined at $5-15^{\circ} \mathrm{C}$ by using $7-\mathrm{EC}$, its deethyl derivative $(7-\mathrm{HC})$, and $\mathrm{BaP}$, respectively, as substrates. ${ }^{65)}$ No effect of an acclimation temperature was observed on the $\mathrm{Q}_{10}$ values of any of the enzymatic reactions (ECOD, ca. 2; UDPGT, ca. 1; BaP hydroxylase, ca. 5). However, higher UDPGT and lower CYP activity were observed for the hepatocytes from fish acclimated at $17^{\circ} \mathrm{C}$ than at $4^{\circ} \mathrm{C}$. Therefore, not only the incubation temperature of an in vitro system but also the acclimation temperature of the fish is one of the key factors in determining the activity of metabolic enzymes.

\subsubsection{Salinity}

The acute toxicity of fenthion to O. mykiss and striped bass (Morone saxatilis) is markedly enhanced by higher salinity of the exposure water, and this change in the former fish is partly accounted for by more formation of its sulfoxide, exhibiting a higher toxicity than the parent pesticide. ${ }^{66)}$ The hepatic microsome of $O$. mykiss acclimated in freshwater $\left(\mathrm{F}_{\mathrm{w}}\right)$ or saline water $\left(\mathrm{S}_{\mathrm{w}}\right)$ produced more sulfoxide than oxon at each formation rate in $S_{w}$ higher than $F_{w}$ by a factor of 5 and 2 , respectively. ${ }^{67)}$ The enzyme inhibition study using ketoconazole (for CYP) and methimazole (for FMO) showed that only CYP was involved in the oxidation of fenthion to its oxon, and both FMO (main contribution) and CYP catalyzed the oxidation to its sulfoxide. The similar in vitro metabolism of aldicarb in O. mykiss showed the salinity-dependent formation of sulfoxide with insignificant CYP involvement. ${ }^{68)}$ The FMO activity in O. mykiss, assayed by thiourea-dependent thiocholine oxidation, markedly increased with salinity in the liver and gills, and the Northern blot analysis showed more expression of FMO mRNA at a higher salinity. In contrast, these salinity effects were not observed in $M$. saxatilis. Three types of FMOs were identified by the transcriptomic analysis of the O. mykiss liver and kidney; up- and downregulated by a higher salinity and salinity-independent. ${ }^{69)}$ The upregulation of FMO mRNA was highly correlated with the formation of sulfoxide in the metabolism of methyl $p$-tolyl sulfide by these microsomes. In the case of $M$. saxatilis, the enzyme inhibition study showed that FMO in the hepatic microsomes oxidized benthiocarb to its sulfoxide, but with no effect of salinity. ${ }^{70)}$ These results imply the salinity induction of FMO in O. mykiss, and the presence of isoforms may cause the different effect of salinity in M. saxatilis. Furthermore, the organ-dependent induction of FMO by salinity (liver $>$ olfactory tissues $>$ gills) was reported in the metabolism of phorate using the microsomes of coho salmon (Oncorhynchus kisutch). ${ }^{71)}$

\subsubsection{Feeding}

Limited energy intake by reducing rations or fasting is reported to downregulate the cellular defense system in O. mykiss, with retained EROD activity but a tentative decrease in GST activity. ${ }^{72}$ This effect was examined by using the hepatocytes prepared from O. mykiss fed full, half, and no rations (fasting). ${ }^{73)}$ The uptake and metabolic rates of $\mathrm{BaP}$ were insensitive to feeding with an almost constant CYP content. However, fasting enhanced the oxidative phase I reactions from 10 to $20 \%$ of the total metabolism, while the phase II conjugations were reduced with the relative contribution of glucuronidation increasing from 60 to $80 \%$.

\subsubsection{Species dependence}

The product analysis through in vitro metabolism studies has sometimes shown significant species differences in metabolic profiles. Carbaryl was metabolized in the liver slices of five species including L. macrochirus and channel catfish (Ictalurus punctatus) mainly via stepwise ring oxidation and conjugation with GA. ${ }^{53)}$ Although common metabolites were detected in the medium, the contribution of the phase I (30-56\%) and II (19-30\%) reactions varied among these species. The speciesdependent activity of EROD, UDPGT, SULT and GST is reported for the hepatic microsomes and cytosol of more than ten species, ${ }^{74,75)}$ which would result in the different composition of free metabolites and their conjugates as above. The different metabolisms in the hepatocytes of O. mykiss and C. carpio were also observed for methoxychlor. Although the oxidative $O$ demethylation proceeded similarly in both species, about three times more formation of the following glucuronide conjugates was observed in O. mykiss. ${ }^{76)}$ The glucuronidation of oxidized metabolites was dominant in the metabolism of $\mathrm{BaP}$ using the hepatocytes of I. nebulosus at about half of the metabolic rate in C. carpio, and more conjugation with GSH proceeded in the latter fish. ${ }^{77)}$ The in vitro system using subcellular fractions showed more quantitative differences in each metabolic reaction. The hepatic microsomes (+ NADPH) of C. carpio oxidized the polyaromatic ring of $\mathrm{BaP}$ twelve times faster than those of I. nebulosus with more formation of 7,8- and 9,10-dihydrodiols (60\% of all metabolites in total) than several quinones which were mainly detected ( $46 \%$ in total) in the latter fish. ${ }^{78)}$ These different profiles of phase I and II metabolites likely originate not only from the species-specific activity of GST, UDPGT and SULT $^{74,75)}$ but also from the presence of various isoforms, as observed with CYP. ${ }^{79)}$ The hepatic S9 fraction of P. promelas had much more activity in both the oxidative desulfuration of parathion and the hydrolysis of its oxon than that of O. mykiss, ${ }^{80)}$ with a greater contribution of enzymatic hydrolysis. Similar profiles were observed in the metabolism of diazinon using the hepatic microsomes of five fish species including O. mykiss, and the relative contribution of oxidation at the alkyl and thiophosphoryl moieties to hydrolysis varied with the species. ${ }^{81)}$ Furthermore, the metabolism of three pharmaceuticals proceeded 1.5-2 times faster in the hepatic $S 9$ of I. punctatus than in that of $O$. 
mykiss, while the opposite trend, 1.5-4 times faster in the latter fish, was observed for the S9 fraction of gills. ${ }^{82)}$

\subsubsection{Organ dependence}

The metabolic activity in subcellular fractions should depend on the corresponding organ used for their preparation. The main metabolites of cis-cypermethrin in the hepatic S9 fraction of $O$. mykiss were the hydroxylated derivative at $4^{\prime}$-position of the phenoxyphenyl ring $\left(4^{\prime}-\mathrm{OH}\right)$ and its glucuronide, while the ester cleavage, followed by oxidation of the gem-methyl group of the cyclopropyl moiety, was dominant in the intestinal S9 fraction. ${ }^{83)}$ A similar trend was observed for the trans-isomer that was more susceptible to enzymatic hydrolysis. The microsomal fraction of this species had much more esterase activity on trans-permethrin in the liver than in the kidney, as evidenced by the inhibition using tetraethylpyrophosphate. ${ }^{64)}$ The different localization of oxidases and esterases was shown by the metabolism of fenthion in O. mykiss. ${ }^{67)}$ Larger oxon and sulfoxide amounts were respectively formed by CYP and CYP/FMO in the microsomes of the liver than of the gills, while the microsomal NADPH-independent esterase activity was much higher in the gills. The liver of this species had significantly higher microsomal EROD activity than the kidney and spleen at a ratio of $32: 2: 1$, and the main metabolites of BaP were different among the organs: $3-\mathrm{OH}$ and 7,8-dihydrodiol in the liver and kidney and 7,8-dihydrodiol and 9-OH in the spleen. ${ }^{84)}$ The phase II conjugation is also organ dependent. About four times higher efficiency was observed in the intestinal microsomes of I. punctatus for the glucuronidation of mono-O-demethylated methoxychlor than in the hepatic ones, while cytosolic sulfonation of the di-O-demethylated metabolite proceeded at two times higher efficiency in the liver than in the intestine. ${ }^{85)}$ Significantly higher GST activity of this species against CDNB was observed in the liver than in the gills, and in the respective cytosol than in the microsomes. ${ }^{86)}$ As a result, more conjugates of chlorothalonil with GSH were formed in the hepatic cytosol.

In summary, the metabolic profiles of pesticides and industrial chemicals studied using several in vitro systems are most likely to depend not only on species and organs but also on the fishkeeping conditions. Since many kinds of metabolic enzymes are distributed at significant levels, liver is the first candidate

Table 3. Metabolism of pesticides using microsomal and/or cytosolic fractions.

\begin{tabular}{|c|c|c|c|c|c|c|c|c|}
\hline Pesticide $^{a)}$ & Species $^{b)}$ & Organ ${ }^{c)}$ & ${ }^{\circ} \mathrm{C}$ & $\operatorname{Pro}^{d)}$ & $\mathrm{Sub}^{e)}$ & Cofactorf) & Metab. code $e^{g)}$ & Ref. \\
\hline Aldrin & $\mathrm{BL}, \mathrm{SM}$ & $\mathrm{L}(\mathrm{m})$ & 25 & $0.1-0.5$ & $3-90$ & - & $\mathrm{O} 1$ & 87 \\
\hline Methoxychlor & $\mathrm{CH}$ & $\mathrm{L}, \mathrm{I}(\mathrm{m})$ & 35 & $0.4-0.6$ & $2-25$ & - & $\mathrm{O} 1$ & 88 \\
\hline OH-der. & $\mathrm{CH}$ & $\mathrm{L}, \mathrm{I}(\mathrm{m}, \mathrm{c})$ & 35 & $0.6-2.5$ & n.a. & UDPGA, PAPS & $\mathrm{C} 1, \mathrm{C} 2$ & 85 \\
\hline Chlorothalonil & $\mathrm{CH}$ & $\mathrm{L}, \mathrm{G}(\mathrm{m}, \mathrm{c})$ & 25 & $0.02-0.5$ & $5-14$ & GSH & $\mathrm{C} 3$ & 86 \\
\hline Atrazine & $\mathrm{ZB}$ & $\mathrm{E}(\mathrm{m}, \mathrm{c})$ & 35 & $0.2-0.4$ & 23 & GSH & $\mathrm{C} 3$ & 89 \\
\hline \multirow[t]{2}{*}{ Aldicarb } & RT & $\mathrm{L}, \mathrm{K}, \mathrm{G}(\mathrm{m})$ & 20 & $0.5-3$ & $20-60$ & - & $\mathrm{O} 2, \mathrm{H}$ & 90 \\
\hline & $\mathrm{CH}$ & $\mathrm{L}(\mathrm{m})$ & r.t. & $0.5-1$ & $33-200$ & - & $\mathrm{O} 2$ & 91 \\
\hline Benthiocarb & ST & $\mathrm{L}(\mathrm{m})$ & 33 & 1.0 & 400 & - & $\mathrm{O} 2$ & 70 \\
\hline Carbofuran & SS & $\mathrm{L}(\mathrm{m})$ & 37 & 7 & 50 & - & $\mathrm{O} 1, \mathrm{H}$ & 92 \\
\hline Eptam & ST & $\mathrm{L}(\mathrm{m})$ & 33 & 1.1 & 200 & - & $\mathrm{O} 2$ & 93 \\
\hline Molinate-SO & $\mathrm{CC}$ & $\mathrm{L}(\mathrm{c})$ & 25 & $1-9$ & 1 & GSH & C3 & 94 \\
\hline Diafenthiuron & RT & $\mathrm{L}(\mathrm{m})$ & 25 & $0.05-0.1$ & n.a. & - & $\mathrm{O} 2$ & 95 \\
\hline Chlorpyrifos & RT,CS & $\mathrm{L}, \mathrm{G}, \mathrm{O}(\mathrm{m})$ & 25 & 1.2 & 100 & - & $\mathrm{O} 2, \mathrm{H}$ & 96 \\
\hline Diazinon & $\mathrm{RT}, \mathrm{CH}$ & $\mathrm{L}(\mathrm{m})$ & 30 & $333^{*}$ & 9 & - & $\mathrm{H}, \mathrm{O} 3, \mathrm{O} 1$ & 81 \\
\hline Fenitrothion & RT,CC & $\mathrm{L}(\mathrm{m}, \mathrm{c})$ & 24 & $50-150 *$ & 70 & GSH & $\mathrm{O} 2, \mathrm{C} 3, \mathrm{H}$ & 97 \\
\hline \multirow[t]{2}{*}{ Fenthion } & SB & $\mathrm{L}(\mathrm{m}, \mathrm{c})$ & 30 & $5-15$ & 200 & 2-OH-P & $\mathrm{O} 2, \mathrm{O} 3, \mathrm{R}$ & 98 \\
\hline & RT & $\mathrm{L}, \mathrm{G}, \mathrm{O}(\mathrm{m})$ & 25 & 1.2 & 100 & - & $\mathrm{O} 2, \mathrm{O} 3, \mathrm{H}$ & 67 \\
\hline Parathion & RT,CS & $\mathrm{L}, \mathrm{G}, \mathrm{O}(\mathrm{m})$ & 25 & 1.2 & 50 & - & $\mathrm{O} 2, \mathrm{H}$ & 96 \\
\hline Phorate & CS & $\mathrm{L}, \mathrm{G}, \mathrm{O}(\mathrm{m})$ & 25 & 1 & 10 & - & $\mathrm{O} 3, \mathrm{O} 2$ & 71 \\
\hline Permethrin & RT,CC & $\mathrm{L}(\mathrm{m})$ & 30 & 6 & $20-40$ & - & $\mathrm{O} 1, \mathrm{H}$ & 99 \\
\hline Conazoles & RT & $\mathrm{L}(\mathrm{m})$ & 11 & 0.13 & $20-40$ & - & $\mathrm{O} 1$ & 100 \\
\hline Triadimefon & RT & $\mathrm{L}(\mathrm{m})$ & 11 & 0.13 & $20-40$ & - & $\mathrm{R}$ & 101 \\
\hline Trifluralin & RT & $\mathrm{L}(\mathrm{m})$ & 25 & 2 & $0.1-0.5$ & - & $\mathrm{O} 1$ & 102 \\
\hline
\end{tabular}

a) $\mathrm{OH}$-der., mono- and di-O-demethylated methoxychlor. Molinate-SO, molinate sulfoxide. Conazoles include bromuconazole, propioconazole, mycobutanil, hexaconazole, triticonazole, diniconazole, febuconazole, uniconazole and paclobutrazole. ${ }^{b}$ See the footnote in Table 1. BL, bluegill (Lepomis macrochirus); CH, channel catfish (Ictalurus punctatus); CS, coho salmon (Oncorhynchus kisutch); SB, sea bream (Pagrus major); SM, smallmouth bass (Micropterus dolomieu); SS, sepat siam (Trichogaster pectoralis); ST, striped bass (Morone saxatilis); ZB, zebrafish (Danio rerio). ${ }^{c}$ L, liver; G, gills; K, kidney; I, intestine; O, olfactory tissues; E, embryo. " $\mathrm{m}$ " and " $\mathrm{c}$ " in the parentheses mean microsomal and cytosolic fractions, respectively. ${ }^{d)}$ Protein concentration of each fraction in $\mathrm{mg} \mathrm{mL}^{-1}$; * in $\mathrm{mg}$ Liver $\mathrm{mL}^{-1} .{ }^{e}$ Pesticide concentration in $\mu \mathrm{M}$; na, not available. ${ }^{f)}$ In the presence of NADPH. UDPGA, uridine 5'-diphospho-glucuronic acid; GSH, reduced glutathione; PAPS, phosphoadenosyl phosphosulfate; 2-OH-P, 2-hydroxypyrimidine. ${ }^{g}$ Metabolism code (see Table 2), in the order of a favorable reaction. r.t., room temperature. n.a., not available. 
organ used for in vitro systems. However, the appropriate organ should be chosen for each pesticide by considering the most probable route of exposure and mode of action. The fishkeeping conditions, such as water temperature, salinity, and the extent of rations, also modify enzyme activity, and hence, they should be as similar as possible between in vitro and in vivo studies. Although the details are not discussed in this review, the preexposure of fish to some chemicals, such as $\beta$-naphthoflavone, 3-methylcholanthrene, and PAHs, is known to differently induce metabolic enzymes. ${ }^{12,22)}$ Therefore, such pretreatment should be avoided unless the character of the enzymes and the effect of environmental contaminants on metabolism are specifically investigated.

\subsection{Metabolism using subcellular fractions}

Microsomal and/or cytosolic fractions have been utilized frequently to examine the reaction kinetics of enzymes participating in the metabolism of pesticides and industrial chemicals. ${ }^{63)}$ Oxidation and conjugation proceed efficiently by adding NADPH or its generating reagents and other cofactors, respectively. This in vitro system has been applied to various pesticides to clarify the specific route(s) of metabolism in relation to their toxicity and bioaccumulation, together with the identification of metabolites, as listed in Table 3. Therefore, the usage of an S9 fraction is expected to give more information on in vivo metabolism. Although the usage of a hepatic S9 fraction to obtain the depletion rate constant of a chemical for IVIVE has become common, ${ }^{15,21)}$ its application to in vitro metabolism is limited, as shown in Table 4. In vitro metabolism using an S9 fraction has been conducted at a protein concentration of $c a .1 \mathrm{mg} \mathrm{mL}^{-1}$ near the acclimation temperature of fish, as recommended by OECD $319 \mathrm{~B}^{21)}$ In the presence of NADPH, CYPs generally catalyze the oxidation of phenyl rings, ${ }^{83,103,107)}$ alkyl groups ${ }^{33,83,103-106,108)}$ including $\mathrm{N}$-demethylation, ${ }^{104,105)}$ and desulfuration of a thiophosphoryl moiety to oxon. ${ }^{80)}$ The succeeding intramolecular rearrangement of 1-hydroxymethyl-1-methylethyl to 2-hydroxy2-methylpropyl was reported as a major secondary reaction for fenproximate. ${ }^{104)}$ Hydrolysis of an ester linkage was observed for parathion $^{80)}$ and trans-permethrin, ${ }^{83,103)}$ most likely by esterases, and the cleavage of ether ${ }^{107)}$ and sulfonamide ${ }^{110)}$ linkages was reported, but with no information on the relevant enzymes. Examples of reductive metabolism are very limited for the debromination of hexabromocyclododecane $(\mathrm{HBCD})^{108)}$ and the aniline formation from 3-trifluoromethyl-4-nitrophenol (TFN). ${ }^{109)}$ Information on phase II reactions has been scarcely reported. The main formation of $\mathrm{O}$-glucuronide was reported for $4^{\prime}-\mathrm{OH}$ cypermethrin ${ }^{83,103)}$ and TFN, ${ }^{109)}$ but the involvement of UDPGT was of minor importance for ibuprofen. ${ }^{106)}$

\subsection{Metabolism using hepatocytes}

Most of the reported studies utilized the primary hepatocytes of O. mykiss, as listed in Table 5, and they were conducted at a cell density of $c a \cdot 10^{6}$ cells $\mathrm{mL}^{-1}$ near the acclimation temperature of fish in accordance with OECD 319A. ${ }^{25)}$ Several examples are known for the in vitro metabolism of pesticides and pharmaceuticals, but with more application to industrial chemicals reported. The main phase I reaction is the oxidation of aromatic rings $s^{38,73,76,111,118,122-125)}$ and alkyl groups ${ }^{33,115,117,118,120,121)}$ including $O$-demethylation, ${ }^{76)}$ similar to that described in the previous section. $N$-hydroxylation has rarely been reported except for 2,4-dichloroaniline ${ }^{112)}$ and 2-acetylaminofluorene (AAF) in O. mykiss. ${ }^{122}$ Regioselective ring oxidation has been reported for biphenyl $(4-\mathrm{OH} / 2-\mathrm{OH}=2.6)^{111)}$ and $\mathrm{BaP}$ (9,10-dihydrodiol/7,8-dihydrodiol $=2-4),{ }^{123,124)}$ and it is highly species dependent in the metabolism of $\mathrm{BaP}$. The terminal carbons at the $\omega / \omega-1$ positions of an alkyl group are some of the most likely candidates for oxidation, as reported for ibuprofen, ${ }^{33)}$ pristine, ${ }^{120}$ and 2,6-diisopropylnaphthalene (DIN), ${ }^{121)}$ but the oxidized position was not restricted for 4-tert-octylphenol. ${ }^{118)}$ The other reaction is the hydrolysis of an amide

Table 4. Metabolism of pesticides and industrial chemicals using S9 subcellular fraction.

\begin{tabular}{|c|c|c|c|c|c|c|c|c|}
\hline Chemical $^{a)}$ & Species $^{b)}$ & $\operatorname{Organ}^{c}$ & ${ }^{\circ} \mathrm{C}$ & $\operatorname{Pro}^{d)}$ & $\mathrm{Sub}^{e)}$ & Cofactor ${ }^{f)}$ & Metab. code ${ }^{g)}$ & Ref. \\
\hline Cypermethrin & RT & $\mathrm{L}$ & 15 & na & 10 & UDPGA & $\mathrm{O} 1, \mathrm{C} 1, \mathrm{H}$ & 83,103 \\
\hline Fenproximate & $\mathrm{CC}$ & $\mathrm{L}$ & 25 & na & 100 & - & $\mathrm{O} 1, \mathrm{M}$ (rearrangement) & 104 \\
\hline Parathion & RT,FM & $\mathrm{L}$ & 11,25 & $10-40 *$ & $50-100$ & - & $\mathrm{H}, \mathrm{O} 3$ & 80 \\
\hline IPA & RT & $\mathrm{L}$ & 22 & 2 & 25 & - & $\mathrm{O} 1$ & 105 \\
\hline Ibuprofen & RT & $\mathrm{L}, \mathrm{G}$ & 15 & $1-2$ & 10 & UDPGA & O1, C1 (L only) & 33,106 \\
\hline$(\mathrm{BrPh})_{2} \mathrm{O}$ & CA & $\mathrm{L}$ & 25 & 1 & 1 & - & O1, M (ether cleavage) & 107 \\
\hline TBBPA & $\mathrm{CA}$ & $\mathrm{L}$ & 25 & 1 & 1 & - & M (ether cleavage) & 107 \\
\hline HBCD & RT & $\mathrm{L}$ & 15 & 1 & $1-10$ & - & $\mathrm{R}, \mathrm{O} 1$ & 108 \\
\hline TFN & RT & $\mathrm{L}, \mathrm{K}$ & 24 & $300 *$ & 100 & UDPGA & $\mathrm{R}, \mathrm{C} 1$ & 109 \\
\hline PFOSA & CA & $\mathrm{L}, \mathrm{K}$ & 20 & 0.5 & 0.04 & - & $\mathrm{H}$ (sulfonamide) & 110 \\
\hline
\end{tabular}

a) IPA, $\mathrm{N}$-(isothiazol-5-yl)phenylacetamide; $(\mathrm{BrPh})_{2} \mathrm{O}, 4,4^{\prime}$-dibromodiphenyl ether; TBBPA, tetrabromo-bisphenol A; HBCD, hexabromocyclododecane; TFN, 3-trifluoromethyl-4-nitrophenol; PFOSA, perfluoro-octane sulfonamide. ${ }^{b)}$ See the footnote in Tables 1 and 3. CA, crucian carp (Carassius aurantus). ${ }^{c)} \mathrm{L}$, liver; $\mathrm{G}$, gills; $\mathrm{K}$, kidney. ${ }^{d)}$ Protein concentration of an $\mathrm{S} 9$ fraction in $\mathrm{mg} \mathrm{mL}^{-1}$; * in $\mathrm{mg} \mathrm{Liver} \mathrm{mL}^{-1}$; na, not available. ${ }^{e}$ Chemical concentration in $\mu \mathrm{M} .{ }^{f)}$ In the presence of NADPH. UDPGA, uridine $5^{\prime}$-diphospho-glucuronic acid. ${ }^{g}$ Metabolism code (see Table 2), in the order of a favorable reaction. 
linkage, as reported for chloramphenicol ${ }^{115)}$ and AAF. ${ }^{122)}$ The dominant conjugation ( $\mathrm{C} 1-\mathrm{C} 3$, metabolism code in Table 2) of phenolic compounds ${ }^{76,11,114,116-118)}$ was $O$-glucuronidation (C1), with a lower contribution of sulfonation (C2 $)^{111,116)}$ and conjugation with GSH (C3). ${ }^{114)}$ Similar metabolic profiles in $O$. mykiss were observed for the phenolic metabolites of biphenyl $\left.(\mathrm{C} 1: \mathrm{C} 2: \mathrm{C} 3=50: 8: 5)^{111}\right)$ and $\left.\mathrm{AAF}(\mathrm{C} 1: \mathrm{C} 2=32: 1){ }^{122}\right)$ Glucuronidation was also the major conjugation for the alcoholic metabolites of chloramphenicol ${ }^{115)}$ and pristane. ${ }^{120)}$ In the case of aniline, $\mathrm{N}$-acetylation was dominant with other phase I and II reactions being minimal, ${ }^{111}$ while the incorporation of electronwithdrawing chlorine atoms into the phenyl ring changed the main reaction to $\mathrm{N}$-glucuronidation. ${ }^{112)}$

\section{Comparison of In Vitro and In Vivo Metabolism}

Before the usefulness and defects of in vitro systems are discussed, we would like to briefly comment on what kind of in vivo data should be compared with the in vitro data. There are several methods of exposing fish to a chemical, including water exposure, force feeding (gavage) using a gelatin capsule, intraperitoneal injection of a solution, and dietary exposure through treated food pellets or prey, and the different routes of exposure may affect the metabolism of a chemical. A glucuronide conjugate of the corresponding pyridinol was mainly excreted to bile and urine when $I$. punctatus was exposed to chlorpyrifos in static water, ${ }^{126)}$ and the same metabolite was detected in the fish administered with pesticide-treated food pellets via oral gavage. ${ }^{127)}$ When O. mykiss was exposed to pentachlorophenol via static water ${ }^{128)}$ or forced feeding, ${ }^{111)}$ almost the same metabolic profiles were observed. About half of the residue in the liver was the parent pesticide, and the remaining was composed mainly of its glucuronide with a trace amount of its sulfate conjugate, while these metabolites ( $68 \%$ and $22 \%$, respectively) dominated the biliary residue. In the case of DDT administered to black sea bream (Acanthopagrus schlegelii), both flow-through water exposure and dietary exposure to the treated shrimp gave similar distributions of DDT and its metabolites (DDT $\gg$ DDD $>$ DDE) in the viscera, gills, and carcass. ${ }^{129)}$ The statistical analysis of the $k_{\mathrm{M}}$ values for about 700 chemicals, derived from water and dietary exposure of O. mykiss and C. carpio, has shown insignificant differences between these exposure because the elimination processes, such as gill ventilation and fecal egestion, are common, irrespective of the exposure. ${ }^{130)}$ The different routes of administration to a fish body, forced feeding and intraperitoneal injection, resulted in more residues of $\mathrm{BaP}$ and its metabolites in the liver and bile of the English sole (Parophrys vetulus) and starry flounder (Platichthys stellatus) by the latter route, while the glucuronide and sulfate conjugates were similarly detected as

Table 5. Metabolism of pesticides and industrial chemicals using hepatocytes.

\begin{tabular}{|c|c|c|c|c|c|c|}
\hline Chemical $^{a)}$ & Species $^{b)}$ & ${ }^{\circ} \mathrm{C}$ & Pro $^{c)}$ & $\operatorname{Sub}^{d)}$ & Metab. code $e^{e)}$ & Ref. \\
\hline Methoxychlor & RT, CA & 15,20 & 2 & 2 & $\mathrm{O} 1, \mathrm{C} 1$ & 76 \\
\hline Pentachlorophenol & RT & 20 & 9 & $10-60$ & $\mathrm{C} 1, \mathrm{C} 2$ & 111 \\
\hline Procloratz & $\mathrm{RT}$ & 20 & $8-10$ & $2-200$ & unknown & 112 \\
\hline Tributyltin & $\mathrm{RT}$ & r.t. & 2 & 1 & M (Sn-C cleavage) & 113 \\
\hline Acetaminophen & $\mathrm{RT}$ & 25 & 6 & 500 & $\mathrm{C} 1, \mathrm{C} 3$ & 114 \\
\hline Chloramphenicol & $\mathrm{RT}$ & 20 & 7 & 12 & $\mathrm{C} 1, \mathrm{H}, \mathrm{O} 1$ & 115 \\
\hline Ibuprofen & $\mathrm{RT}$ & 15 & 1 & 10 & $\mathrm{O} 1$ & 33 \\
\hline Aniline & $\mathrm{RT}$ & 20 & 9 & $10-60$ & $\mathrm{C} 4, \mathrm{O} 1, \mathrm{C} 1, \mathrm{C} 2$ & 111 \\
\hline 2,4-Dichloroaniline & RT & 20 & $8-10$ & 50 & $\mathrm{O} 3$ & 112 \\
\hline 1-Naphthol & PL & 23 & $0.8-4.7$ & $20-200$ & $\mathrm{C} 1, \mathrm{C} 2$ & 116 \\
\hline 4-Nonylphenol & $\mathrm{RT}$ & 18 & 1 & 10 & $\mathrm{C} 1, \mathrm{O} 1$ & 117 \\
\hline 4-tert-Octylphenol & $\mathrm{RT}$ & 15 & 10 & 30 & $\mathrm{C} 1, \mathrm{O} 1$ & 118 \\
\hline Bisphenol-S & $\mathrm{ZB}$ & 28 & 0.4 & 1 & $\mathrm{C} 1$ & 119 \\
\hline Biphenyl & RT & 20 & 9 & $10-60$ & $\mathrm{O} 1, \mathrm{C} 1, \mathrm{C} 2, \mathrm{C} 3$ & 111 \\
\hline Pristane & RT & 22 & 21 & 13 & $\mathrm{O} 1$ & 120 \\
\hline DIN & $\mathrm{CC}$ & 25 & 20 & 5 & $\mathrm{O} 1$ & 121 \\
\hline AAF & $\mathrm{RT}$ & 24 & 1.5 & $7-65$ & $\mathrm{O} 1, \mathrm{C} 1, \mathrm{H}, \mathrm{C} 2, \mathrm{O} 3$ & 122 \\
\hline \multirow[t]{5}{*}{$\mathrm{BaP}$} & $\mathrm{RT}$ & 10 & $50^{*}$ & 20 & $\mathrm{O} 1, \mathrm{C} 1, \mathrm{C} 2$ & 73 \\
\hline & CT & 20 & 0.25 & 4 & $\mathrm{O} 1, \mathrm{C} 1, \mathrm{C} 2$ & 38 \\
\hline & CC,BB & 28 & $1-3^{*}$ & 40 & $\mathrm{O} 1, \mathrm{C} 1, \mathrm{C} 3, \mathrm{C} 2$ & 123,124 \\
\hline & $\mathrm{BB}$ & 28 & $1-3^{*}$ & 40 & $\mathrm{O} 1, \mathrm{C} 1, \mathrm{C} 3, \mathrm{C} 2$ & 124 \\
\hline & ES & 17 & 10 & $2-40$ & $\mathrm{O} 1, \mathrm{C} 1, \mathrm{C} 3$ & 125 \\
\hline
\end{tabular}

Primary hepatocytes were used except Ref. 33 (spheroids) and 38 (monolayer). ${ }^{a)}$ DIN, 2,6-diisopropyl-naphthalene; AAF, 2-acetylaminofluorene; BaP, benzo[a]pyrene. ${ }^{b}$ See the footnote in Tables 1, 3 and 4. PL, plaice (Pleuronectes platesia); BB, brown bullhead (Ictalurus nebulosus); ES, English sole (Parophrys vetulus). ${ }^{c)}$ hepatocyte concentration in $10^{6}$ cells $\mathrm{mL}^{-1}$; * in $\mathrm{mg}$ cell $\mathrm{mL}^{-1} .{ }^{d)}$ Chemical concentration in $\mu \mathrm{M} .{ }^{e}$ ) Metabolism code (see Table 2), in the order of a favorable reaction. r.t., room temperature. 
main metabolites in both species. ${ }^{131)}$

Second, metabolic profiles are highly dependent on the fish species, as observed with in vitro systems. The metabolic activity against diazinon by flow-through water exposure decreased in the order of loach (Misgurnus anguillicaudatus) $>0$. mykiss $>C$. carpio with the dominant formation of the corresponding pyrimidinol, but the propenyl derivative of diazinon was not detected in the loach. ${ }^{132)}$ Under the static water exposure of five species including O. mykiss to pentachlorophenol, the major conjugate in bile, glucuronide or sulfate, was highly dependent on the species. ${ }^{133)}$ Metabolite analysis of the liver by the dietary exposure of C. carpio and O. mykiss to methoxychlor showed higher CYP-catalyzed $O$-demethylation activity but lower UDPGT activity in the former species. ${ }^{76)}$ Species dependence not only in metabolic activity but also in the regioselectivity of CYP-catalyzed ring oxidation was observed in bile when phenanthrene in a gelatin capsule was force-fed to three marine fish. ${ }^{134)}$ Furthermore, the activity of UDPGT and SULT varied significantly among fourteen fish species under static water exposure to pyrene. ${ }^{75)}$

By taking account of several controlling factors of in vitro systems described in Section 2, together with the above information, in vitro and in vivo metabolism should be compared for the relevant organ of the same species. Although the route of exposure is unlikely to be of importance to metabolic profiles, the fishkeeping conditions and metabolisms should be as close as possible between in vitro and in vivo studies. Appropriate examples focusing on subcellular fractions and hepatocytes are compared below with the in vivo metabolism of pesticides and industrial chemicals, keeping the above notes in mind.

\subsection{Pesticides}

\subsubsection{Organophosphorus pesticides}

The product analysis of the exposure water and fish showed that fenitrothion was metabolized in O. mykiss via ester cleavage, oxidative desulfuration to oxon, and $O$-demethylation. ${ }^{97)}$ Although an in vitro study using the hepatic microsomes (+ NADPH) and cytosol (+ GSH) of the fish confirmed the relevant metabolic reactions, in vivo metabolite distribution could not be qualitatively deduced. Ester hydrolysis of chlorpyrifos proceeded 25-54 times faster than oxidative desulfuration in the hepatic microsomes of I. punctatus (+ NADPH), but the phenol glucuronide, the main metabolite in urine and bile under static water exposure, was not formed probably due to the insufficient amount of UDPGA for conjugation. ${ }^{126)}$ In vitro metabolism of fenthion and its sulfoxide was conducted by using the hepatic microsomes and cytosol of goldfish (Carassius auratus), respectively. ${ }^{98)}$ Several enzyme inhibition studies showed the involvement of CYP and FMO in the formation of sulfoxide, and its reduction to fenthion was likely catalyzed by aldehyde oxidase. These results accounted for the formation of each metabolite when each of them was intraperitoneally injected to the fish, but only qualitatively. ${ }^{135)}$ By exposing O. mykiss to diazinon in flow-through water, the corresponding pyrimidinol and propenyl metabolites were detected at a relative ratio of $15: 1$ in the $\mathrm{CHCl}_{3}$-iso PrOH extract of the fish homogenate. ${ }^{132)}$ This profile was reproduced at a ratio of $22: 1$ by using its hepatic microsomes (+ NADPH) ${ }^{81)}$ The pyrimidinol glucuronide was the main metabolite by in vitro metabolism using the liver slices of O. mykiss. ${ }^{56)}$ However, it failed to be detected under the water-exposure conditions, probably due to the insufficient extraction of the polar conjugates by organic solvents.

\subsubsection{Organochlorines}

In the urine from O. mykiss with pentachlorophenol administered by forced feeding, about $70 \%$ of the residue was the parent pesticide, and the remaining residue consisted of glucuronide and sulfate conjugates at a ratio of $1: 2$, while in the bile, $>90 \%$ of the residue consisted of conjugates at a corresponding ratio of $3: 1{ }^{111)}$ The biliary metabolite pattern was qualitatively similar in the fish under water exposure. ${ }^{128,133)}$ In vitro metabolism of this pesticide using the hepatocytes of O. mykiss showed that ca. $40 \%$ of the residue in the medium was made up of the above conjugates at a ratio of $7: 1,{ }^{111)}$ showing the difficulty in estimating the distribution of metabolites. After flow-through water exposure of O. mykiss to chlorothalonil, $60-70 \%$ of the biliary metabolites were mono- and disubstituted GSH conjugates. ${ }^{136)}$ These were confirmed by in vitro metabolism using the corresponding hepatic cytosol with GSH, but with no information on their relative amounts available. ${ }^{137)}$ In the case of methoxychlor administered to this species via diets, the major hepatic metabolites after 14 days were glucuronide conjugates of mono- and di-O-demethylated derivatives at an approximate ratio of $5: 2$, amounting to $44 \%$ of the residues in total. ${ }^{76)}$ The methanol extract of the in vitro metabolism system using the corresponding hepatocytes contained the above conjugates (50\% and $13 \%$, respectively, after $4 \mathrm{hr}$ ) as the main metabolites. Furthermore, liver slices from this species were found to produce the same metabolites ( $28 \%$ and $25 \%$, respectively, after $8 \mathrm{hr}){ }^{54,55)}$ These results show the usefulness of hepatocytes and liver slices to qualitatively estimate the in vivo metabolism of methoxychlor. In vitro studies using the hepatic microsomes (+ UDPGA) and cytosol (+ PAPS) of I. punctatus showed a formation rate of glucuronide conjugate ten-times higher than the sulfate one from the $O$ demethylated metabolite, ${ }^{85)}$ which partly explains the detection of glucuronides as dominant components in the bile and liver of the force-fed fish. ${ }^{138)}$

\subsubsection{Pyrethroids}

The main biliary metabolites of cis-cypermethrin with the static water exposure of $\mathrm{O}$. mykiss were a $4^{\prime}-\mathrm{OH}$ derivative and its glucuronide, representing $80-90 \%$ of the residue in total. ${ }^{103)}$ The metabolites via ester cleavage increased up to $c a$. $40 \%$ for the trans-isomer, with the above metabolites still primary. The sulfate and taurine conjugates amounted to less than $3 \%$ for both isomers. In vitro metabolism using the hepatic S9 fraction of this species in the presence of NADPH and UDPGA reproduced these metabolic profiles of both isomers quite well, but the formation of glucuronides was reduced and taurine conjugates were not produced. ${ }^{83)}$ Concerning permethrin, the gluc- 
uronide conjugate of $4^{\prime}$-OH derivatives of cis/trans-isomers was predominate in the bile of $O$. mykiss after static exposure, but no quantitative information on metabolites was reported. ${ }^{139)}$ In vitro metabolism using the corresponding hepatic microsomes accounted for the involvement of CYP in both ring hydroxylation and ester cleavage, but no information on glucuronidation was available. ${ }^{64,140)}$

\subsubsection{Others}

Molinate was almost completely metabolized in C. carpio under static water exposure, and the main metabolites in water were $3-\mathrm{OH}$ and 4 -keto (33\% of the applied dose in total), followed by sulfoxide (4\%) and $4-\mathrm{OH}(2 \%) .{ }^{141)}$ In vitro metabolism using the corresponding hepatic microsomes $(+\mathrm{NADPH})$ reproduced this pattern quite well. The trace formation of the mercapturic acid derivative was confirmed by using the hepatic cytosol (+GSH). ${ }^{94)}$ Incidentally, one pharmaceutical example is available for comparison. The main biliary metabolites of ibuprofen after the flow-through water exposure of $O$. mykiss were acyl-glucuronide conjugates of the parent compound and several hydroxylated derivatives, followed by a $2-\mathrm{OH}$ derivative hydroxylated at the isobutyl methine carbon. ${ }^{142)}$ In vitro metabolism using its hepatic S9 fraction (+NADPH and UDPGA) gave a 2-OH and acyl-glucuronide of ibuprofen, ${ }^{106)}$ while LC-MS/MS analysis of the extracts in the other study similarly using the S9 fraction and hepatocytes indicated the formation of a $1-\mathrm{OH}$ derivative hydroxylated at the isobutyl methylene carbon and two unknown hydroxylated metabolites, respectively. ${ }^{33)}$

\subsection{Industrial chemicals}

The metabolism of biphenyl and aniline in O. mykiss was studied using not only forced feeding but also hepatocytes. ${ }^{111)}$ The metabolite analysis of bile and urine showed more favorable hydroxylation of biphenyl at the 4-position than at the 2-position, and the conjugation of these metabolites with GA was dominant, followed by those with sulfate and GSH. These profiles were reproduced quite well using the hepatocytes. The other study using liver slices of this species showed the oxidation activity comparable to that with hepatocytes. ${ }^{50)}$ The major metabolism of aniline was $\mathrm{N}$-acetylation by forced feeding, which was similarly observed in the hepatocytes, but the ring oxidation at the 2- and 4-positions followed by conjugation rarely occurred. ${ }^{111)}$ The differences in either the uptake rate between two chemicals or the efficiency of each enzyme might cause the apparent inconsistency of metabolic profiles in the hepatocytes. The different metabolism was similarly observed for 2,4-dichloroaniline. ${ }^{112)}$ The corresponding $N$-glucuronide was more efficiently formed in the hepatocytes than was the $\mathrm{N}-\mathrm{OH}$ derivative, while the conjugate was a single metabolite in both urine and bile with forced feeding. In addition to phenyl ring oxidation, the oxidative cleavage of an ether linkage was reported in the metabolism of $4,4^{\prime}$-dibromodiphenyl ether using the hepatic S9 fraction of the crucian carp (Carassius carassius). ${ }^{107)}$ Two hydroxylated metabolites and bromophenol were identified via GC-MS after their derivatization, and the absence of NADPH failed to produce them. The main metabolites in the crucian carp's liver after semistatic water exposure were mono- and dihydroxylated derivatives and bromophenol, ${ }^{143)}$ in agreement with the in vitro metabolism. There remains a possibility of microbial metabolism in the gut for the in vivo formation of debrominated metabolites.

The phase II conjugation with GA is frequently observed for phenols. The main metabolite of bisphenol-S in adult $D$. rerio with semistatic water exposure was mono-glucuronide (79\% of the residue) with a minor formation of sulfate conjugate $(8 \%),{ }^{61)}$ while its hepatocytes mainly produced mono-glucuronide with a trace amount of di-glucuronide. ${ }^{119)}$ Incidentally, the hepatocytes of $O$. mykiss well reproduced not only the ECOD activity but also the conjugation rates of 1-naphthol with GA and sulfate in its liver slices. ${ }^{50)}$ Therefore, much less SULT activity against bisphenol- $S$ or fewer inappropriate procedures of the hepatocyte preparation may account for the observed inconsistency in D. rerio. In vivo metabolism of 4-nonylphenol in O. mykiss has been extensively studied using force-fed administration. ${ }^{144,145)}$ Higher residues consisting of ten polar metabolites were detected in bile. GC-MS analysis after derivatization identified them to be glucuronides, whose aglycon was mainly the parent phenol followed by metabolites formed via stepwise $\beta$-oxidation of the alkyl chain. The major metabolites in its hepatocytes were the same as in in vivo studies, with the additional formation of several glucuronides of unknown hydroxylated metabolites. ${ }^{17)}$ The glucuronide of 4-tert-octylphenol was mainly detected in the liver and bile of O. mykiss via flow-through water exposure to the phenol, with formation of the catechol glucuronide in a lesser amount. ${ }^{146)}$ These profiles were reproduced using O. mykiss hepatocytes, and the glucuronides of hydroxylated derivatives at the 2- or 4-position of the butyl moiety were additionally formed. ${ }^{118)}$

The metabolism of hydrophobic $\mathrm{BaP}$ has been extensively studied in several species in relation to its bioaccumulation. With the intraperitoneal or intra-arterial injection of $\mathrm{BaP}$ into fish, most of the biliary metabolites were polar and unextractable by organic solvents, e.g., $86 \%$ in 0 . mykiss $^{147)}$ and $>97 \%$ in P. vetulus. ${ }^{131)}$ Polar metabolites in the medium incubating the hepatocytes and bile of each species were enzymatically hydrolyzed by $\beta$-glucuronidase and arylsulfatase, and the subsequent HPLC analysis of their extracts showed that the glucuronide conjugates were dominant in many cases (Fig. 1A). Similar conjugation profiles between the bile and hepatocytes were observed in C. carpio, while the proportion of glucuronides was higher in the hepatocytes of O. mykiss, ${ }^{73)}$ I. nebulosus ${ }^{77,124)}$ and P. vetulus. ${ }^{97)}$ The main aglycons were $3-\mathrm{OH}$ and 7,8-dihydrodiol derivatives in the liver of $O$. mykiss under intraperitoneal administration, and this metabolic pattern was mostly reproduced by the hepatic microsomes (+ NADPH) with more formation of $9-\mathrm{OH},{ }^{84)}$ as shown in Fig. 1B. In contrast, quinones were dominant as aglycons in the medium of hepatocytes, followed by $3-\mathrm{OH}$ and diol derivatives. ${ }^{38)}$ The main free metabolite commonly detected in the bile ${ }^{147)}$ and hepatocytes ${ }^{38)}$ of O. mykiss 
(A)

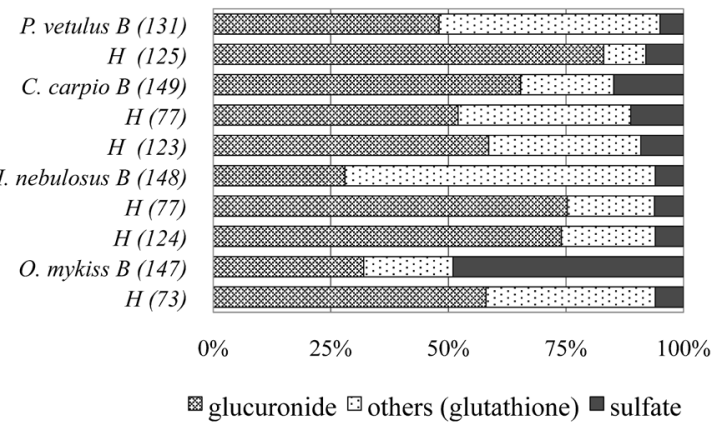

(B)
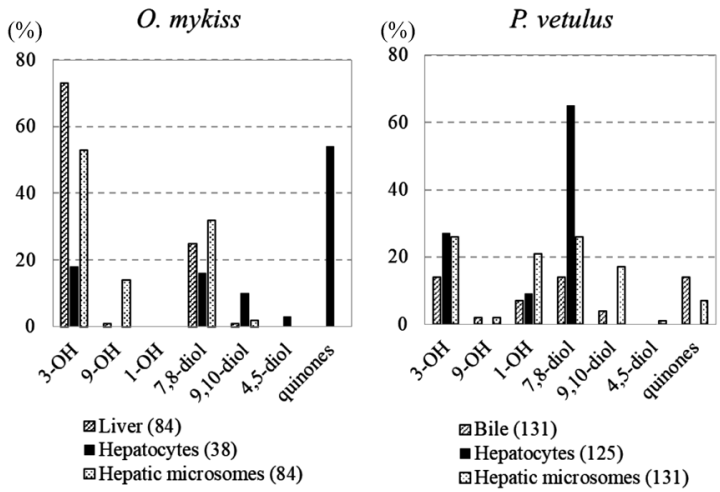

Fig. 1. Metabolic profiles of $\mathrm{BaP}$ in several species. The corresponding reference number appears in parentheses. (A) Proportion of each conjugate. $\%$ others (glutathione $)=100-(\%$ glucuronide $+\%$ sulfate $) . \mathrm{H}$ : hepatocytes after incubation for 1-2 hr. B: bile from the fish after intraperitoneal administration for 1-3 days (Ref. 147, intra-arterially). The glucuronide/ sulfate ratio of 9/1 was assumed in Ref. 131. (B) Proportion of aglycon after enzymatic hydrolysis of conjugates. Liver and bile from the fish after intraperitoneal administration for 3-5 days. Hepatocytes and hepatic microsomes were incubated for $1.5-2 \mathrm{hr}$ and $15 \mathrm{~min}-2 \mathrm{hr}$, respectively.

was 3-OH, while quinones and dihydrodiols appeared at comparable levels in the bile. These results may indicate the different conjugation capability between $O$. mykiss and its hepatocytes against the primary metabolites of $\mathrm{BaP}$. The biliary residues of $P$. vetulus with intraperitoneal injection mostly consisted of polar metabolites, about half of which were GSH conjugates. ${ }^{131)}$ The remaining components were glucuronides and sulfates at a ratio of $8-10: 1$, with the main aglycons of $3-\mathrm{OH}, 7,8$-dihydrodiol, and several quinones (Fig. 1A and B). Analysis of the medium incubating $P$. vetulus hepatocytes showed the glucuronide conjugates of 3-OH and 7,8-dihydrodiol as main components, but the presence of quinones, sulfate and GSH conjugates was not clarified. ${ }^{125)}$ Further similarities in the aglycon pattern were observed between the bile and hepatic microsomes. More than $90 \%$ of the biliary metabolites formed via intraperitoneal injection to I. nebulosus $^{148)}$ and C. carpio $^{149)}$ were polar with the half of them resistant to enzymatic hydrolysis, and the ratio of glucuronides and sulfates was $5: 1$. When $\mathrm{BaP}$ was incubated with the corresponding hepatocytes of $I$. nebulosus ${ }^{77,124)}$ and C. carpio, ${ }^{77,123)}$ the percentage of each conjugate decreased in the order of glucuronide $(51-74 \%)>$ GSH $(18-36 \%)>$ sulfate $(6-11 \%)$ conjugates, partly accounting for the in vivo conjugation patterns. However, many more free biliary metabolites, especially 9,10-dihydrodiol, were detected with both hepatocyte systems than with intraperitoneal injection.

\subsection{Comparison of metabolic profiles}

There is an essential difficulty in comparing in vitro and in vivo metabolism. The former is the cross section of the latter and deals with the part of in vivo metabolism by using subcellular fractions and cells originating from a specific organ, while the latter is an average metabolism in the whole fish and gives metabolites in the representative organ (liver) and fraction (plasma, bile, urine). Furthermore, the incubation period of in vitro systems generally ranges from 1 to $4 \mathrm{hr}$ due to the limitations of enzyme activity and cell viability, while the in vivo exposure of fish to a chemical lasts days to weeks. If the controlling factors discussed in Section 2 are taken into account, these differences make the comparison of metabolism somewhat obscure.

As pointed out in many reviews, ${ }^{3,12,16)}$ both the microsomes and cytosol of a specific organ, such as the liver, kidney and gills, are conveniently used to examine the action of metabolic enzymes, but one may be misled with regard to the main metabolism when key cofactors are absent. As compared with these sys-

Table 6. Characteristics of in vitro systems.

\begin{tabular}{|c|c|c|}
\hline In vitro system & Main activity & Merits/limitations \\
\hline Microsomes & CYP, FMO, UDPGT & $\begin{array}{l}\text { Specific metabolic pathway in any organ; addition of the corresponding cofactor is prerequisite } \\
\text { for enzyme activity; able to be preserved. }\end{array}$ \\
\hline Cytosol & GST, SULT & \\
\hline both fractions & esterases & \\
\hline $\begin{array}{l}\text { Post-mitochondrial } \\
\text { fraction (S9) }\end{array}$ & all, except acyl transferases & $\begin{array}{l}\text { Easy to prepare from several organs and able to be preserved; addition of multiple cofactors is } \\
\text { prerequisite for enzyme activity; does not include the membrane transport process. }\end{array}$ \\
\hline Hepatocytes & all & $\begin{array}{l}\text { Cumbersome to prepare from liver but able to be preserved; transformed from primary cells to } \\
\text { spheroids by aggregation with the changes of enzyme activity; can account for the membrane } \\
\text { transport process. }\end{array}$ \\
\hline Cell lines & all & $\begin{array}{l}\text { Easy to obtain from the commercial source and to use; activity may not always reflect that of the } \\
\text { original tissue. }\end{array}$ \\
\hline Tissue slices & all & $\begin{array}{l}\text { Closest model of tissue having intact membranes with tissue architecture; diffusion limitations } \\
\text { may affect a metabolic rate; can not be preserved. }\end{array}$ \\
\hline
\end{tabular}


tems, the usage of an S9 fraction and hepatocytes is more likely to give information relevant to in vivo metabolism. Not only enzymatic hydrolysis and oxidation but also conjugation with GA, sulfate and GSH are well reproduced, but the regioselectivity of CYP-catalyzed oxidation and the extent of each conjugation depend on each in vitro system. So, the contribution of phase I and II reactions is sometimes different between in vitro and in vivo studies. As a result, the present analysis, though based on the limited data available, at least indicates the usefulness of in vitro systems for qualitatively estimating the metabolism of pesticides and industrial chemicals in fish.

\section{Conclusion}

The characteristics of each in vitro system in this review are summarized in Table 6. It is necessary to select an appropriate system by considering what kind of endpoint is desired for metabolism. The present literature survey clearly indicates the convenience of in vitro systems, especially using an S9 fraction and hepatocytes, to qualitatively grasp the metabolic profiles of pesticides. Since some studies have been conducted without a radiolabel, the quantitative discussion on metabolism is difficult. In the case of hepatocytes, a medium analysis without a material balance is frequently observed, and the product distribution in the cells is rarely available. Furthermore, the preparation of analytical samples for HPLC and MS is very different among the studies, and whether to directly analyze liquid samples or to extract each component using a solvent system depends on each study design. Pretreatment of the medium and extracts, such as the enzymatic hydrolysis of conjugates, is an additional issue prior to instrumental analyses. In any case, it is highly recommended for in vitro metabolism that an appropriate radiolabel is used to characterize the distribution and to identify each metabolite through extraction and enzyme treatment.

Although it is a conventional approach, in vitro metabolism using an S9 fraction is very limited, as compared with microsomes and cytosol. From the ease of preparation from any organ relevant to metabolism together with its possible preservation, its applicability to pesticides whose information on in vivo metabolism in several species is available should be further investigated. The cofactor NADPH is mostly used in the previous studies, but rarely for others, such as UDPGA; hence, the relevant cofactors should be added appropriately, in accordance with OECD 319B. When a pesticide and its metabolites have a carboxyl or amino group, the possible conjugation with an amino acid, such as taurine and/or $\mathrm{N}$-acylation, should be examined separately using a mitochondrial fraction of the liver or kidney. Slightly more metabolic information is available for hepatocytes, but it is still very limited for pesticides. Most studies have been conducted using primary hepatocytes, freshly prepared or by separating viable ones after thawing cryopreserved ones. Since incubation for longer than a week integrates cells into spheroids with the formation of cell-to-cell junctions and variation in the enzyme activity, the effects of these changes on metabolism should be further investigated.
Based on these data, the metabolic profiles of pesticides, preliminarily obtained using in vitro systems, would play a great role in identifying key issues in their toxicity and bioaccumulation and, as a result, in minimizing the number of fish used for ecotoxicological assessment.

\section{References}

1) European Food Safety Authority: EFSA J. 11, 268 (2013).

2) J. P. Cravedi: Rev. Med. Vet. 153, 419-424 (2002).

3) D. Schlenk: "Biochemistry and Molecular Biology in Fishes," ed. by T. P. Mommsen and T. W. Moon, Vol. 6, Chapt. 6, Elsevier Science, Amsterdam, pp. 171-190, 2005.

4) K. B. Tierney, C. J. Kennedy, F. Gobas, M. Gledhill and M. Sekela: "Organic Chemical Toxicology of Fishes," ed. by K. B. Tierney, A. P. Farrell and C. J. Brauner, Vol. 33, Chapt. 1, Academic Press, San Francisco, pp. 1-52, 2014.

5) B. Austin: Sci. World J. 6, 931-945 (2006).

6) M. Matthies, K. Solomon, M. Vighi, A. Gilman and J. V. Tarazona: Environ. Sci. Process. Impacts 18, 1114-1128 (2016).

7) European Commission: "Working document on the nature of pesticide residues in fish," SANCO/11187/2013 rev. 3, Brussels, Belgium, p. 35, 2013.

8) S. Scholz, E. Sela, L. Blaha, T. Braunbeck, M. Galay-Burgos, M. García-Franco, J. Guinea, N. Klüver, K. Schirmer, K. Tanneberger, M. Tobor-Kapłon, H. Witters, S. Belanger, E. Benfenati, S. Cretonm, M. T. D. Cronin, R. I. L. Eggen, M. Embry, D. Ekman, A. Gourmelon, M. Halder, B. Hardy, T. Hartung, B. Hubesch, D. Jungmann, M. A. Lampi, L. Lee, M. Léonard, E. Küster, A. Lillicrap, T. Luckenbach, A. J. Murk, J. M. Navas, W. Peijnenburg, G. Repetto, E. Salinas, G. Schüürmann, H. Spielmann, K. E. Tollefsen, S. Walter-Rohde, G. Whale, J. R. Wheeler and M. J. Winter: Regul. Toxicol. Pharmacol. 67, 506-530 (2013).

9) K. Rehberger, C. Kropf and H. Segner: Environ. Sci. Eur. 30, 12 (2018).

10) OECD Guideline for the Testing of Chemicals 305 (2012).

11) J. A. Arnot, D. Mackay and M. Bonnell: Environ. Toxicol. Chem. 27, 341-351 (2008).

12) D. Schlenk, M. Celander, E. P. Gallagher, S. George, M. James, S. W. Kullman, P. van den Hurk and K. Willett: "The Toxicology of Fishes," ed. by R. T. Di Giulio and D. E. Hinton, Chapt. 4, CRC Press, Boca Raton, pp. 153-234, 2008.

13) A. V. Weisbrod, J. Sahi, H. Segner, M. O. James, J. Nichols, I. Schultz, S. Erhardt, C. Cowan-Ellsberry, M. Bonnell and B. Hoeger: Environ. Toxicol. Chem. 28, 86-96 (2009).

14) E. Papa, L. van der Wal, J. A. Arnot and P. Gramatica: Sci. Total Environ. 470-471, 1040-1046 (2014).

15) OECD Guidance Document, Series on Testing and Assessment No. 280, OECD Publishing, Paris, p. 47 (2018).

16) J. Nichol, S. Erhardt, S. Dyer, M. James, M. Moore, K. Plotzke, H. Segner, I. Schultz, K. Thomas, L. Vasiluk and A. Weisbrod: Hum. Ecol. Risk Assess. 13, 1164-1191 (2007).

17) J. W. Nichols, D. B. Huggett, J. A. Arnot, P. N. Fitzsimmons and C. E. Cowan-Ellsberry: Environ. Toxicol. Chem. 32, 1611-1622 (2013).

18) J. Nichols, K. Fay, M. J. Bernhard, I. Bischof, J. Davis, M. Halder, J. Hu, K. Johanning, H. Laue, D. Nabb, C. Schlechtriem, H. Segner, J. Swintek, J. Weeks and M. Embry: Toxicol. Sci. 164, 563-575 (2018).

19) R. T. Mingoia, K. P. Glover, D. L. Nabb, C.-H. Yang, S. I. Snajdr and X. Han: Environ. Sci. Technol. 44, 3052-3058 (2010).

20) M. G. Baron, K. S. Mintram, S. F. Owen, M. J. Hetheridge, A. J. 
Moody, W. M. Purcell, S. K. Jackson and A. N. Jha: PLoS One 12, 13 (2017).

21) OECD Guideline for the Testing of Chemicals 319B (2018).

22) M. O. James: "Xenobiotic Conjugation Chemistry," ed. by G. D. Paulson, J. Caldwell, D. H. Hutson and J. J. Menn, ACS Symp. Ser. 299, Chapt. 2, American Chemical Society, Washington D. C., pp. 29-47, 1986.

23) M. O. James and J. B. Pritchard: Drug Metab. Dispos. 15, 665-670 (1987).

24) L. Förlin and T. Andersson: Comp. Biochem. Physiol. 80B, 569-572 (1985).

25) OECD Guideline for the Testing of Chemicals 319A (2018).

26) H. Segner: Comp. Biochem. Physiol. 120A, 71-81 (1998).

27) K. A. Fay, P. N. Fitzsimmons, A. D. Hoffman and J. W. Nichols: Xenobiotica 44, 345-351 (2014).

28) K. A. Fay, R. T. Mingoia, I. Goeritz, D. L. Nabb, A. D. Hoffman, B. D. Ferrell, H. M. Peterson, J. W. Nichols, H. Segner and X. Han: Environ. Sci. Technol. 48, 8170-8178 (2014).

29) M. G. Baron, W. M. Purcell, S. K. Jackson, S. F. Owen and A. N. Jha: Ecotoxicology 21, 2419-2429 (2012).

30) M. Pesonen and T. B. Andersson: Aquat. Toxicol. 37, 253-267 (1997).

31) G. Flouriot, G. Monod, Y. Valotaire, A. Devaux and J.-P. Cravedi: Mar. Environ. Res. 39, 293-297 (1995).

32) J.-P. Cravedi, A. Paris, G. Monad, A. Devaux, G. Flouriot and Y. Valotaire: Comp. Biochem. Physiol. 113C, 241-246 (1996).

33) C. Uchea, S. Sarda, T. Schulz-Utermoehl, S. Owen and K. J. Chipman: Xenobiotica 43, 421-431 (2013).

34) C. Uchea, S. F. Owen and J. K. Chipman: Toxicol. Res. 4, 494-507 (2015)

35) K. A. Fay, P. N. Fitzsimmons, A. D. Hoffman and J. W. Nichols: Environ. Toxicol. Chem. 36, 463-471 (2017).

36) A. Sturm, J. P. Cravedi, E. Perdu, M. Baradat and H. Segner: Aquat. Toxicol. 53, 229-245 (2001).

37) T. L. Weimer, A. P. Reddy, U. Harttig, D. Alexander, S. C. Stamm, M. R. Miller, W. Baird, J. Hendricks and G. Bailey: Toxicol. Sci. 57, 217-228 (2000).

38) M. Ferraris, M. K. Dosanjh and E. Marafante: Polycycl. Aromat. Compd. 11, 91-98 (1996).

39) X. Han, D. L. Nabb, C.-H. Yang, S. I. Snajdr and R. T. Mingoia: Environ. Toxicol. Chem. 28, 481-488 (2009).

40) K. A. Connors, B. Du, P. N. Fitzsimmons, A. D. Hoffman, C. K. Chambliss, J. W. Nichols and B. W. Brooks: Environ. Toxicol. Chem. 32, 1810-1818 (2013).

41) J. W. Nichols, A. D. Hoffman, T. L. ter Laak and P. N. Fitzsimmons Toxicol. Sci. 136, 359-372 (2013).

42) J. S. Bearr, C. L. Mitchelmore, S. C. Roberts and H. M. Stapleton: Aquat. Toxicol. 124-125, 41-47 (2012).

43) S. C. Thornton, L. Diamond and W. M. Baird: J. Toxicol. Environ. Health 10, 157-167 (1982).

44) I. Leguen, C. Carlsson, E. Perdu-Durand, P. Prunet, P. Pärt and J. P. Cravedi: Aquat. Toxicol. 48, 165-176 (2000).

45) L. M. Langan, G. M. Harper, S. F. Owen, W. M. Purcell, S. K. Jackson and A. N. Jha: Ecotoxicology 26, 1117-1133 (2017).

46) T. Lammel, G. Tsoukatou, J. Jellinek and J. Sturve: Ecotoxicol. Environ. Saf. 167, 250-258 (2019).

47) M. E. Franco, G. E. Sutherland and R. Lavado: Comp. Biochem. Physiol. 206-207, 32-40 (2018).

48) J. Stadnicka-Michalak, F. T. Weiss, M. Fischer, K. Tanneberger and K. Schirmer: Environ. Sci. Technol. 52, 3091-3100 (2018).
49) L. M. Langan, S. Arossa, S. F. Owen and A. N. Jha: Mutat. Res. 826, 53-64 (2018).

50) Y. Singh, J. B. Cooke, D. E. Hinton and M. G. Miller: Drug Metab. Dispos. 24, 7-14 (1996).

51) J. P. Cravedi, E. Perdu-Durand and A. Paris: Comp. Biochem. Physiol. 121C, 267-275 (1998).

52) M. Eide, O. A. Karlsen, H. Kryvi, P. A. Olsvik and A. Goksøyr: Aquat. Toxicol. 153, 110-115 (2014).

53) B. H. Chin, L. J. Sullivan and J. E. Eldridge: J. Agric. Food Chem. 27, 1395-1398 (1979).

54) K. Ohyama, S. Maki, K. Sato and Y. Kato: Xenobiotica 34, 741-754 (2004).

55) K. Ohyama: "Environmental Fate and Safety Management of Agrochemicals," ed. by J. M. Clark and H. Ohkawa, ACS Symp. Ser. 899, Chapt. 16, American Chemical Society, Washington D. C., pp. 185-194, 2005.

56) M. A. Tapper, J. A. Serrano, P. K. Schmieder, D. E. Hammermeister and R. C. Kolanczyk: Appl. In Vitro Toxicol. 4, 13-23 (2018).

57) T. Katagi: Rev. Environ. Contam. Toxicol. 204, 1-132 (2010).

58) J. T. Ahokas: "Pesticide and Xenobiotic Metabolism in Aquatic Organisms," ed. by M. A. Q. Khan, J. J. Lech and J. J. Menn, ACS Symp. Ser. 99, Chapt. 17, American Chemical Society, Washington D. C., pp. 279-296, 1979.

59) M. J. Leaver, J. Wright, P. Hodgson, E. Boukouvala and S. G. George: Aquat. Toxicol. 84, 356-365 (2007).

60) D. J. Clarke, S. G. George and B. Burchell: Aquat. Toxicol. 20, 35-56 (1991).

61) V. Le Fol, F. Brion, A. Hillenweck, E. Perdu, S. Bruel, S. Aït-Aïssa, J.-P. Cravedi and D. Zalko: Int. J. Mol. Sci. 18, 1-14 (2017).

62) R. Pedersen and E. M. Hill: Environ. Sci. Technol. 36, 3275-3283 (2002).

63) P. N. Fitzsimmons, G. J. Lien and J. W. Nichols: Comp. Biochem. Physiol. 145C, 485-506 (2007).

64) A. H. Glickman and J. J. Lech: Toxicol. Appl. Pharmacol. 60, 186192 (1981).

65) T. Andersson and U. Koivusaari: Aquat. Toxicol. 8, 85-92 (1986).

66) O. Bawardi, J. Rimoldi and D. Schlenk: Pestic. Biochem. Physiol. 88, 321-327 (2007).

67) R. Lavado, J. M. Rimoldi and D. Schlenk: Toxicol. Appl. Pharmacol. 235, 143-152 (2009).

68) J. Wang, S. Grisle and D. Schlenk: Toxicol. Sci. 64, 200-207 (2001).

69) R. Lavado, R. Aparicio-Fabre and D. Schlenk: Comp. Biochem. Physiol. 157C, 9-15 (2013).

70) J. R. Cashman, L. D. Olsen, R. S. Nishioka, E. S. Gray and H. A. Bern: Chem. Res. Toxicol. 3, 433-440 (1990).

71) R. Lavado, L. A. Maryoung and D. Schlenk: Environ. Sci. Technol. 45, 4623-4629 (2011).

72) M. E. Gourley and C. J. Kennedy: Comp. Biochem. Physiol. 150C, 270-278 (2009).

73) C. J. Kennedy and K. B. Tierney: Aquat. Toxicol. 90, 172-181 (2008).

74) J. F. González, R. Reimschuessel, B. Shaikh and A. S. Kane: Mar. Environ. Res. 67, 183-188 (2009).

75) Y. Ikenaka, M. Oguri, A. Saengtienchai, S. M. M. Nakayama, S. Ijiri and M. Ishizuka: Environ. Toxicol. Pharmacol. 36, 567-578 (2013).

76) I. Bischof, J. Köster, H. Segner and C. Schlechtriem: Comp. Biochem. Physiol. 187C, 62-73 (2016).

77) A. R. Steward, J. Zaleski, R. C. Gupta and H. C. Sikka: Mar. Environ. Res. 28, 137-140 (1989).

78) H. C. Sikka, J. P. Rutkowski and C. Kandaswami: Aquat. Toxicol. 16, 101-112 (1990) 
79) E. Funari, A. Zoppini, A. Verdina, G. de Angelis and L. Vittozzi: Ecotoxicol. Environ. Saf. 13, 24-31 (1987).

80) K. B. Wallace and J. E. Dargan: Toxicol. Appl. Pharmacol. 90, 235242 (1987)

81) Y. Fujii and S. Asaka: Bull. Environ. Contam. Toxicol. 29, 455-460 (1982).

82) C. F. Gomez, L. Constantine and D. B. Huggett: Chemosphere 81 1189-1195 (2010).

83) R. Edwards, P. Millburn and D. H. Hutson: Pestic. Sci. 21, 1-21 (1987).

84) A.-M. Möller, C. Hermsen, T. Floehr, M. H. Lamoree and H. Segner Drug Metab. Dispos. 42, 111-118 (2014).

$85)$ M. O. James, L. D. Stuchal and B. A. Nyagode: Aquat. Toxicol. 86, 227-238 (2008).

86) E. P. Gallagher, G. L. Kedderis and R. T. Di Giuliob: Biochem. Pharmacol. 42, 139-145 (1991)

87) R. H. Stanton and M. A. Q. Khan: Pestic. Biochem. Physiol. 3, 351357 (1973).

88 ) L. D. Stuchal, K. M. Kleinow, J. J. Stegeman and M. O. James: Drug Metab. Dispos. 34, 932-938 (2006).

89) C. Wiegand, E. Krause, C. Steinberg and S. Pflugmacher: Ecotoxicol. Environ. Saf. 49, 199-205 (2001).

90) D. Schlenk and D. R. Buhler: Xenobiotica 21, 1583-1589 (1991).

91) E. J. Perkins, A. El-Alfy and D. Schlenk: Toxicol. Sci. 48, 67-73 (1999).

92) S. S. Gill: Bull. Environ. Contam. Toxicol. 25, 697-701 (1980).

93) J. R. Cashman, L. D. Olsen, G. Young and H. Bern: Chem. Res. Toxicol. 2, 392-399 (1989).

94) M. M. Lay and J. J. Menn: Xenobiotica 9, 669-673 (1979).

95) H. Kayser and P. Eilinger: Pest Manag. Sci. 57, 975-980 (2001)

96) R. Lavado and D. Schlenk: Aquat. Toxicol. 101, 57-63 (2011).

97) J. Miyamoto, Y. Takimoto and K. Mihara: "Pesticide and Xenobiotic Metabolism in Aquatic Organisms," ed. by M. A. Q. Khan, J. J. Lech and J. J. Menn, ACS Symp. Ser. 99, Chapt. 1, American Chemical Society, Washington D. C., pp. 3-20, 1979.

98) S. Kitamura, T. Suzuki, T. Kadota, M. Yoshida, K. Ohashi and S. Ohta: Drug Metab. Dispos. 31, 179-186 (2003).

99) A. H. Glickman, T. Shono, J. E. Casida and J. J. Lech: J. Agric. Food Chem. 27, 1038-1041 (1979).

100) C. S. Mazur and J. F. Kenneke: Environ. Sci. Technol. 42, 947-954 (2008).

101) J. F. Kenneke, D. R. Ekman, C. S. Mazur, B. J. Konwick, A. T. Fisk, J. K. Avants and A. W. Garrison: Chirality 22, 183-192 (2010).

102) I. R. Schultz and W. L. Hayton: Aquat. Toxicol. 26, 287-306 (1993).

103) R. Edwards, P. Millburn and D. H. Hutson: Xenobiotica 17, 11751193 (1987)

104) K. Motoba, H. Nishizawa, T. Suzuki, H. Hamaguchi, M. Uchida and S. Funayama: Pestic. Biochem. Physiol. 67, 73-84 (2000).

105) J. J. Sheets, A. Schmidt, J. G. Samaritoni and J. M. Gifford: J. Agric. Food Chem. 45, 4826-4832 (1997).

106) C. F. Gomez, L. Constantine, M. Moen, A. Vaz, W. Wang and D. B. Huggett: Bull. Environ. Contam. Toxicol. 86, 247-251 (2011).

107) M. Shen, J. Cheng, R. Wu, S. Zhang, L. Mao and S. Gao: Aquat. Toxicol. 114-115, 73-79 (2012).

108) M. A.-E. Abdallah, C. Uchea, J. K. Chipman and S. Harrad: Environ. Sci. Technol. 48, 2732-2740 (2014).

109) J. J. Lech and N. V. Costrini: Comp. Gen. Pharmacol. 3, 160-166 (1972).

110) M. Chen, L. Qiang, X. Pan, S. Fang, Y. Han and L. Zhu: Environ. Sci. Technol. 49, 13817-13824 (2015).
111) J. P. Cravedi, A. Lafuente, M. Baradat, A. Hillenweck and E. PerduDurand: Xenobiotica 29, 499-509 (1999).

112) J. P. Cravedi, G. Boudry, M. Baradat, D. Rao and L. Debrauwer: Aquat. Toxicol. 53, 159-172 (2001).

113) S. Reader, R. Saint Louis, É. Pelletier and F. Denizeau: Environ. Toxicol. Chem. 15, 2049-2052 (1996).

114) R. S. Parker, M. T. Morrissey, P. Moldeus and D. P. Selivonchick: Comp. Biochem. Physiol. 70B, 631-633 (1981).

115) J. P. Cravedi and M. Baradat: Comp. Biochem. Physiol. 100C, 649652 (1991).

116) H. Morrison, P. Young and S. George: Biochem. Pharmacol. 34, 3933-3938 (1985)

117) N. G. Coldham, S. Sivapathasundaram, M. Dave, L. A. Ashfield, T. G. Pottinger, C. Goodall and M. J. Sauer: Drug Metab. Dispos. 26, 347-354 (1998).

118) R. T. Pedersen and E. M. Hill: Xenobiotica 30, 867-879 (2000).

119) V. Le Fol, S. Aït-Aïssa, N. Cabaton, L. Dolo, M. Grimaldi, P. Balaguer, E. Perdu, L. Debrauwer, F. Brion and D. Zalko: Environ. Sci. Technol. 49, 3860-3868 (2015).

120) J. P. Cravedi, E. Perdu-Durand, M. Baradat and J. Tulliez: Mar. Environ. Res. 28, 15-18 (1989).

121) H. Kojima, M. Tanaka and T. Yoshida: Ecotoxicol. Environ. Saf. 9, 364-368 (1985)

122) A. R. Steward, S. A. Elmarakby, K. G. Stuart, S. Kumar and H. C. Sikka: Toxicol. Appl. Pharmacol. 130, 188-196 (1995).

123) J. Zaleski, A. R. Steward and H. C. Sikka: Carcinogenesis 12, 167174 (1991).

124) A. R. Steward, J. Zaleski and H. C. Sikka: Chem. Biol. Interact. 74, 119-138 (1990)

125) M. Nishimoto, G. K. Yanagida, J. E. Stein, W. M. Baird and U. Varanasi: Xenobiotica 22, 949-961 (1992).

126) M. G. Barron, S. M. Plakas, P. C. Wilga and T. Ball: Environ. Toxicol. Chem. 12, 1469-1476 (1993).

127) M. G. Barron, S. M. Plakas and P. C. Wilga: Toxicol. Appl. Pharmacol. 108, 474-482 (1991).

128) A. H. Glickman, C. N. Statham, A. Wu and J. J. Lech: Toxicol. Appl. Pharmacol. 41, 649-658 (1977).

129) R. W. M. Kwong, P. K. N. Yu, P. K. S. Lam and W.-X. Wang: Environ. Toxicol. Chem. 27, 2053-2063 (2008).

130) J. A. Arnot, D. Mackay, T. F. Parkerton and M. Bonnell: Environ. Toxicol. Chem. 27, 2263-2270 (2008).

131) U. Varanasi, M. Nishimoto, W. L. Reichert and B.-T. Le Eberhart: Cancer Res. 46, 3817-3824 (1986).

132) K. Seguchi and S. Asaka: Bull. Environ. Contam. Toxicol. 27, 244249 (1981).

133) G. R. Stehly and W. L. Hayton: Xenobiotica 19, 75-81 (1989).

134) J. E. Solbakken and K. H. Palmork: Comp. Biochem. Physiol. 70C, 21-26 (1981)

135) S. Kitamura, T. Kadota, M. Yoshida and S. Ohta: J. Health Sci. 45, 266-270 (1999).

136) P. E. Davies: Aquat. Toxicol. 7, 265-275 (1985).

137) P. E. Davies: Aquat. Toxicol. 7, 277-299 (1985).

138) B. A. Nyagode, M. O. James and K. M. Kleinow: Toxicol. Sci. 108, 320-329 (2009)

139) A. H. Glickman, A. A. R. Hamid, D. E. Rickert and J. J. Lech: Toxicol. Appl. Pharmacol. 57, 88-98 (1981).

140) M. G. Nillos, S. Chajkowski, J. M. Rimoldi, J. Gan, R. Lavado and D. Schlenk: Chem. Res. Toxicol. 23, 1568-1575 (2010).

141) M.-M. Lay, A. M. Niland, J. R. Debaun and J. J. Menn: "Pesticide and Xenobiotic Metabolism in Aquatic Organisms," ed. by M. A. Q. 
Khan, J. J. Lech and J. J. Menn, ACS Symp. Ser. 99, Chapt. 6, American Chemical Society, Washington D. C., pp. 95-119, 1979.

142) M. Lahti, J.-M. Brozinski, A. Jylhä, L. Kronberg and A. Oikari: Environ. Toxicol. Chem. 30, 1403-1411 (2011).

143) J. Cheng, L. Mao, Z. Zhao, M. Shen, S. Zhang, Q. Huang and S. Gao: Chemosphere 86, 446-453 (2012).

144) R. Thibaut, L. Debrauwer, D. Rao and J.-P. Cravedi: Xenobiotica 28, 745-757 (1998).

145) R. Thibaut, L. Debrauwer, D. Rao and J. P. Cravedi: Sci. Total Environ. 233, 193-200 (1999).
146) A. M. R. Ferreira-Leach and E. M. Hill: Mar. Environ. Res. 51, 75-89 (2001).

147) J. M. Seubert and C. J. Kennedy: Arch. Environ. Contam. Toxicol. 38, 342-349 (2000).

148) A. R. Stewatd, C. Kandaswami, S. Chidambaram, C. Ziper, J. P. Rutkowski and H. C. Sikka: Environ. Toxicol. Chem. 9, 1503-1512 (1990).

149) A. R. Steward, C. Kandaswami, S. Chidambaram, C. Ziper, J. P. Rutkowski and H. C. Sikka: Aquat. Toxicol. 20, 205-218 (1991). 